Tomás Urani

Composição da Dívida e Efeitos Patrimoniais de Câmbio nas Empresas Brasileiras 
Tomás Urani

\title{
Composição da Dívida e Efeitos Patrimoniais de Câmbio nas Empresas Brasileiras
}

\author{
Dissertação de Mestrado submetida ao \\ Corpo Docente do Departamento de Econo- \\ mia da Universidade de Brasília como parte \\ dos requisitos necessários para obtenção do \\ título de Mestre em Economia.
}

Universidade de Brasília

Departamento de Economia

Orientador: Prof. Roberto de Góes Ellery Junior

Brasília

13 de abril de 2016 


\section{Agradecimentos}

Em primeiro lugar, à minha mãe, pelo amor, carinho, apoio e exemplo ao longo de toda a minha vida.

Ao meu pai, que não está mais aqui, mas foi minha maior fonte de inspiração nessa jornada.

À minha família, em especial à Valéria, ao Giuseppe e aos meus irmãos, Pedro, Luca e Francisco.

À minha namorada e grande companheira Luiza, sem o seu amor, apoio e paciência eu não teria chegado até aqui.

Ao meu orientador, Roberto Ellery, pela atenção, dedicação e pelos conselhos de grande importância para a conclusão deste trabalho.

Ao meu coorientador e grande amigo Marco Bonomo, pelos conselhos, pela atenção e pela dedicação, na dissertação e em muitos outros momentos importantes da minha vida.

À minha querida orientadora de graduação Marina Figueira de Mello, pela confiança depositada em mim, sendo de crucial importância na minha decisão de ingressar na pós-graduação.

Ao professor Joaquim Andrade, pela atenção e por toda a rica convivência que tivemos ao longo do meu mestrado.

À Gabriela Cruz, pela grande ajuda que me deu nos primeiros passos da dissertação.

Ao Rudi Rocha, pela atenção e conselhos preciosos.

Ao meu caro amigo Pedro, aos seus pais, Luciana e Gustavo, ao seu irmão Lucas, e à Leninha, por terem me acolhido como um membro da família enquanto estive em Brasília. 
À todos os meus amigos, que sempre me apoiaram e estiveram comigo ao longo dos momentos mais alegres e mais difíceis da minha vida, inclusive me visitando inúmeras vezes enquanto estive em Brasília, fazendo com que o período longe de casa se tornasse menos difícil. 


\section{Resumo}

Neste trabalho é analisada a interação entre o ambiente macroeconômico e as decisões individuais das firmas desde a livre flutuação do câmbio em 1999. Num primeiro momento, estima-se a influência do ambiente macroeconômico na estrutura da dívida das firmas. É possível ver que o fator de maior importância para que firmas possam obter endividamento de longo prazo e endividamento em moeda estrangeira é o tamanho das mesmas. Isto é, empresas maiores têm mais acesso ao mercado de crédito de longo prazo e ao mercado de crédito estrangeiro. Em seguida, estima-se os efeitos patrimoniais das variações cambiais, com base no investimento realizado pelas empresas. Os efeitos não são significantes, mas tornamse negativos e altamente significantes ao se inserir um controle para exportação e importação a nível setorial. Ao controlar para imperfeições nos mercados de capitais, usando a medida $\mathrm{Q}$ de Tobin, os resultados voltam a ser insignificantes, apontando que outros fatores podem ser mais importantes nas decisões das firmas nacionais.

Palavras-chaves:Investimento, Efeitos Patrimoniais, Taxa de Câmbio, Crédito. 


\begin{abstract}
In this work we focus on the interaction between the macroeconomic environment and firms individual decisions since Brazil started a free-float regime in 1999. In a first moment, we estimate the influence of the macroeconomic environment inf firms debt structure. It is possible to observe that the major factor influencing that firms obtain long terms financing or financing in foreign currency is the size of the firms. In other words, larger firms have more access to long term and external credit than smaller ones. The following step was to estimate exchange rate balance sheet effects observing firms investment. The results are inconclusive in a first estimation, but became negative and highly significant when controlled for exportation and importation. However, those same results turned to be inconclusive again when controlled for capital market imperfections using the Tobin's Q, witch indicates that there are other factors playing a more important role in firms decisions.
\end{abstract}

Keywords: Investment, Balance Sheet Effects, Exchange Rate, Credit. 


\section{Sumário}

1 Introdução . . . . . . . . . . . . . . . . . . . 7

2 Base de Dados ........................... . 8

3 Ambiente Macroeconômico e Institucional . . . . . . . . . . . . . . . . 11

4 Literatura . . . . . . . . . . . . . . . . . . . . 15

5 Composição da Dívida . . . . . . . . . . . . . . . . . . . . . . 21

5.1 Motivação . . . . . . . . . . . . . . . . . . 21

5.2 Estratégia . . . . . . . . . . . . . . . . . . . 23

5.3 Resultados . . . . . . . . . . . . . . . . . . . 24

6 Efeitos Patrimoniais de Câmbio . . . . . . . . . . . . . . . . . . 26

6.1 Motivação . . . . . . . . . . . . . . . . . . . 26

6.2 Estratégia . . . . . . . . . . . . . . . . 26

6.3 Resultados . . . . . . . . . . . . . . . . . . . 27

7 Análise Setorial . . . . . . . . . . . . . . . . . . . . . 29

8 Efeitos Patrimoniais em Mercados de Capitais Imperfeitos . . . . . . . . . . 30

9 Conclusão . . . . . . . . . . . . . . . . . . . . . . 31

Referências . . . . . . . . . . . . . . . . . 32

$\begin{array}{ll}\text { Anexos } & 34\end{array}$

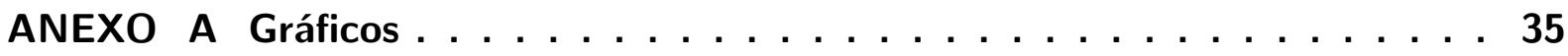

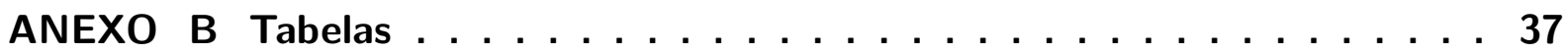




\section{Introdução}

Diante das crises cambiais ocorridas em países emergentes na década de 90, surgiram novos modelos na tentativa de explicá-las com base nas escolhas das firmas. Estes modelos, chamados de modelos de terceira geração, têm o objetivo de avaliar como as perdas patrimoniais, oriundas de variações cambiais, sofridas pelas firmas endividadas em moeda estrangeira afetam as suas decisões. A deterioração do patrimônio das empresas faz com que estas vejam reduzidas as suas capacidades de investimento, o que acelera o processo recessivo da desvalorização cambial. Vale ressaltar que, como apontado em Bernanke e Gertler (1995), efeitos patrimoniais em investimento ocorrem apenas diante de imperfeições nos mercados de capitais.

Para analisar como as firmas reagem diante de variações cambiais, os chamados modelos de terceira geração fazem uso de dados contábeis a nível de firma, assim como dados relativos ao ambiente macroeconômico. A ideia é que as decisões das empresas influenciam e são influenciadas mutuamente pelo ambiente macroeconômico.

Neste trabalho, o objetivo não é estudar uma crise cambial específica. Porém, a metodologia desenvolvida nos modelos de terceira geração é usada para entender os efeitos patrimoniais, oriundos de variação cambial, nas empresas brasileiras desde a estabilização da moeda nacional. Para isso, construiu-se uma base de dados contendo os balanços patrimoniais de todas as empresas não financeiras listada na Bolsa de Valores de São Paulo desde 1995.

O estudo pode ser decomposto em duas partes. Num primeiro momento estudase a interação entre o ambiente macroeconômico e a composição das dívidas das firmas. A ideia é ver como o ambiente macroeconômico afeta as decisões de financiamento das empresas brasileiras. São estimadas duas equações, com o objetivo de entender como as empresas brasileiras reagem a variações cambiais e a variações na inflação. Após analisar a composição da divida das empresas, o estudo se concentra em estimar os efeitos patrimoniais de câmbio no investimento. Para isso, criou-se uma variável para o investimento das empresas, permitindo uma estimação de como a variação cambial afeta as suas decisões de investimento.

Na seção 2 é apresentada uma descrição mais detalhada da base de dados usada no estudo. Na seção 3 é apresentado um arcabouço macroeconômico do período analisado. Na seção seguinte é estudada a composição das dívidas das empresas. E, finalmente, nas seções de 5 a 8 estuda-se o efeito patrimonial de câmbio, considerando diversos controles possíveis. 


\section{Base de Dados}

Para realizar o estudo foi necessário criar uma base de dados contendo informações de todas as empresas não financeiras listadas na Bolsa de Valores de São Paulo. O início do período amostral se deu no primeiro trimestre de 1995 e se estende até o segundo trimestre de 2015. É importante ressaltar que, em meados de 2010, as empresas brasileiras passaram por uma grande reforma contábil. A partir do terceiro trimestre de 2010 todas as empresas listadas na Comissão de Valores Mobiliários (CVM) se adequaram às normas do IFRS (International Financial Reporting Standards), que são as normas contábeis internacionais. Desde então, mais informações são disponibilizadas pelas companhias, dentro de um padrão mais rígido e de mais fácil entendimento. A data de corte se deu no momento do início do estudo. A base de dados inicia-se em 1995, primeiro ano do mandato do presidente Fernando Henrique Cardoso e primeiro ano após a estabilização da moeda com o Plano Real, em 1994. As transformações da sociedade e da economia brasileira após a estabilização da moeda torna tal período particularmente interessante de ser estudado, e serão tratadas na próxima seção. Todas as informações a nível de empresa foram obtidas na base de dados da Economática.

Tentou-se também inserir informações de empresas de capital fechado, isto é, empresas não listadas na Bolsa de Valores de São Paulo, o que não foi possível diante da dificuldade em obter as informações necessárias ou da pouca precisão das informações encontradas. Não foi possível, com os dados disponíveis, encontrar informações relevantes sobre a composição das dívidas das empresas não-listadas. Vale destacar que, pela legislação brasileira, empresas brasileiras de capital fechado não são obrigadas a divulgar balanços e, caso os divulguem, os mesmos não necessariamente são auditados, contrariamente às empresas listadas. Esses dois aspectos resultaram na não inclusão de empresas de capital fechado no estudo.

A base de dados contém informações de 506 empresas não financeiras listadas na bolsa de valores de São Paulo no período amostral. Para cada uma delas foram coletadas 14 variáveis de interesse. Estas variáveis são: Ativo Total, Ativo Imobilizado, Receitas com Vendas e Serviços, Fluxo de Caixa, Dívida Total (soma da dívida total de curto prazo com a dívida total de longo prazo), Dívida total de Curto Prazo (decomposta em: dívida em moeda nacional, dívida em moeda estrangeira, arrendamento financeiro e debêntures), Dívida Total de Longo Prazo (decomposta em: dívida em moeda nacional, dívida em moeda estrangeira, arrendamento financeiro e debêntures) e, por último, foi criada uma variável para o investimento. O ideal seria poder ter uma medida do gasto com capital da empresa, chamado de CAPEX. Porém, tal dado não está disponível nos balanços das empresas. Por isso, foi criada uma medida para o investimento, que é a taxa de variação 
do ativo imobilizado somada a depreciação ocorrida no período. Esta é a medida mais tradicional e a mais utilizada na literatura de finanças corporativas. A inserção dos ativos (total e imobilizado) das empresas na base de dados é particularmente importante pois serão usadas como medidas do capital das mesmas. Nas estimações que usarem a terceira medida de investimento, que é a taxa de variação do ativo total, a proxy para o capital da firma será o ativo total, nas demais, que consideram variações do ativo imobilizado (com e sem depreciação), a proxy para o capital será o ativo imobilizado. Todas as variáveis da base de dados, fora as taxas de investimento, estão corrigidas pelo IPCA, encontrando-se em valores reais de julho de 2015 .

Outro dado importante coletado foi a evolução dos repasses do BNDES. Além destes repasses, o crédito direcionado (crédito destinado a determinados setores ou atividades com recursos regulados por lei ou normativo) e o crédito total do setor financeiro foram considerados. É importante notar que, no Brasil, o maior agente fornecedor de crédito de longo prazo para atividades de investimento é o Banco Nacional de Desenvolvimento Econômico e Social (para outros fins, como habitação, os principais agentes também são bancos públicos). Estes dados relacionados ao crédito na economia brasileira são disponibilizados pelo site do Banco Central do Brasil, onde também foram coletadas informações relativas a inflação (IPCA), série história da taxa de juros básica (SELIC) e série da taxa de câmbio. Este último dado será observado como dólar comercial para compra no fechamento de cada período (como o importante para o estudo é a variação, poderia-se também usar outra série), e foi usado para o cálculo da taxa de câmbio real. Informações relativas à Taxa de Juros de Longo Prazo (TJLP) praticada pelo BNDES foram encontradas no site do próprio banco.

Por último, foram coletados junto à CVM dados sobre os ADRs (American Depositary Receipts) das empresas brasileiras. Os ADRs são títulos emitidos por empresas brasileiras nos Estados Unidos e são equivalentes a recibos de ações dessas empresas que são negociados na bolsa de valores de Nova Iorque. ADRs podem ser uma importante variável de controle.

Doidge, Karolyi e Stulz (2001) mostram que empresas estrangeiras (não norteamericanas) que possuem ADRs costumam ter maior valor de mercado do que as empresas do mesmo país que não possuem ADRs. Uma causa disto é o fato de que, com ADRs, as empresas têm acesso à um maior número de fontes de financiamento e consequentemente podem ter uma capacidade de investimento maior do que as outras empresas de seus países que não possuem ADR. Porém, a principal explicação oferecida pelos autores é que empresas com ADRs na bolsa de valores de Nova Iorque são regidas por normas mais rígidas por conta das agências reguladoras norte-americanas, o que garante maior transparência e tem impactos positivos na qualidade da gestão das empresas, consequentemente, no desempenho das mesmas. 
Janot e Novaes (2009) também serviu como base para esta questão pois ele aponta que empresas brasileiras com ADR possuem uma maior eficiência na gestão cambial. Os motivos apontados, assim como em Doidge, Karolyi e Stulz (2001), são as pressões disciplinadoras presentes no mercado norte-americano. Deve-se considerar também que, em geral, empresas que possuem ADR são geralmente as maiores e mais antigas empresas dos seus países, o que já as oferece um leque mais amplo de possibilidades de financiamento. Tais observasões fazem com que seja importante considerar os ADRs neste estudo, pois empresas com melhor gestão cambial são menos passíveis de sofrerem perdas patrimoniais diante de uma forte desvalorização cambial 


\section{Ambiente Macroeconômico e Institucional}

O período observado é particularmente interessante dada a história do país. Neste período o país consolidou-se como uma democracia moderna com instituições sólidas, foi capaz de estabilizar a moeda depois de um período de hiperinflação crônica, além de avançar em questões econômicas e sociais. Um ano chave no período amostral foi 1999 quando, após a reeleição do presidente Fernando Henrique Cardoso, o Banco Central permitiu a flutuação livre do câmbio.

É importante mencionar os principais momentos de turbulência econômica vividos pelo país ao longo do período estudado. No final da década de 90, antes da flexibilização do câmbio, houve uma severa crise cambial afetando mercados emergentes, principalmente o mercado asiático, sendo um dos fatores que influenciaram a flutuação cambial no Brasil. Foi inclusive essa crise cambial que estimulou a elaboração dos primeiros modelos de terceira geração. Outro período de turbulência foi no ano de 2002, antes da eleição do presidente Lula. O então candidato Lula apresentava, supostamente, uma ameaça aos investidores por conta das suas propostas vistas como populistas e pouco responsáveis do ponto de vista da estabilidade econômica. Porém, ao ser eleito e dar continuidade as políticas de seu antecessor, inclusive aprofundando algumas medidas, o presidente Lula rapidamente passou credibilidade ao mercado financeiro, fazendo com que o país embarcasse num período de considerável crescimento econômico. Deve ser destacado também que, este período de forte crescimento, contou com a ajuda do boom dos preços das commodities, impulsionado principalmente pelo forte crescimento chinês. Em 2008 o país enfrentou outra forte turbulência por conta da grave crise financeira internacional, mas foi superada rapidamente, com uma retomada de crescimento já em 2010. É importante destacar que, para atenuar os efeitos da crise, foram tomadas medidas anticíclicas, mudando consideravelmente as diretrizes da política econômica. Com a eleição da presidente Dilma houve um aprofundamento das mudanças na política econômica que haviam iniciado no final do governo Lula. Atualmente o país vive um período de grande instabilidade econômica que vem se deteriorando desde 2014. A moeda nacional vem perdendo valor, a inflação volta a preocupar, chegando a $10.67 \%$ em 2015, o PIB vem encolhendo e o desemprego aumentando.

Por último, é importante mencionar que, em 2015, o Brasil perdeu o grau de investimento dado pela agência de classificação de risco Standards $\&$ Poor's (S\&P). No final do ano, foi a vez da segunda agência de classificação de risco, a Fitch, retirar o grau de investimento do país. Com duas das três principais agências de classificação de risco qualificando o título brasileiro como especulativo, o Brasil perde oficialmente o grau de investimento que havia sido conquistado em 2008. Em sequência, no início de 2016 
foi a vez da terceira agência, a Moody's retirar o selo de bom pagador do país. Esses rebaixamentos refletem nas dívidas das empresas nacionais que terão cada vez mais dificuldades e, consequentemente, pagarão cada vez mais caro para conseguir financiamento no exterior. É importante ressaltar que a perda do grau de investimento ocorreu após o período amostral, porém é claramente uma consequência direta da deterioração do cenário econômico que já vinha ocorrendo. após o segundo rebaixamento do país, o Ministro da Fazenda Joaquim Levy renunciou ao cargo, sendo sucedido por Nelson Barbosa, então Ministro do Planejamento.

Na Figura 1 é possível observar a evolução das taxas de juros reais e nominais, da inflação e da meta de inflação. Um primeiro ponto importante na análise do gráfico é observar que, desde a criação do sistema de metas de inflação (em 1999), raras foram as ocasiões em que o centro da meta foi atingido. Em quase todo o período observado a inflação acumulada em 12 meses manteve-se superior ao centro da meta estabelecido pelo Conselho Monetário Nacional (CMN). Pode-se verificar que, em 2011, houve uma redução da taxa de juros mesmo diante de um cenário de pressão inflacionária. Pode-se observar também que, no período, houve uma forte queda da taxa de juros básica na economia, a SELIC. Porém, nos últimos anos é possível observar um aumento da taxa SELIC, que não tem sido capaz de conter o aumento da inflação. A recente queda na taxa de juros real em 2015 é explicada exatamente pelo fato de que a inflação tem subido em ritmo mais alto do que a taxa de juros nominal.

É interessante também observar a trajetória do câmbio, real e nominal, na Figura 2. Desde o estabelecimento de um regime de câmbio flutuante em 1999 o país passou por quatro momentos particularmente interessantes. O primeiro foi após a flexibilização do regime cambial, quando o país enfrentou a primeira forte desvalorização já no primeiro mês de 1999. O segundo veio com a eleição do presidente Lula, que levou a uma forte especulação sobre o rumo que a economia brasileira tomaria. Após eleito, Lula deu continuidade às políticas econômicas de FHC, como já mencionado, e a taxa de câmbio foi gradualmente diminuindo. O terceiro momento interessante foi no segundo semestre de 2008, diante da forte crise financeira internacional, quando a taxa de câmbio nominal passou de 1.55 para 2.32 num espaço de cinco meses. Com a rápida recuperação da economia brasileira, em menos de um ano a moeda já estava cotada abaixo de 1.80. O quarto e último momento se deu a partir de 2012, quando a moeda americana entrou numa trajetória de valorização quase constante e encerrou o período observado cotada em mais de 3.50 reais. Vale notar que, em setembro de 2015 a moeda americana chegou no seu maior valor, cotada em 4.24 reais.

Não se pode falar de mercado de crédito e investimento no Brasil sem destacar a participação do BNDES. Com uma carteira de crédito de mais 660 bilhões de reais em meados de 2015, o BNDES é o maior banco de desenvolvimento do mundo, na frende de 
grandes instituições como o Banco Mundial. Há tempos o BNDES é um agente importante na economia brasileira e um dos principais agentes no mercado de crédito nacional principalmente quando se trata do mercado de crédito de longo prazo. Porém, a atuação do BNDES aumentou consideravelmente após a crise de 2008 e continuou assim ao longo do primeiro governo Dilma.

As taxas de juros oferecidas pelo BNDES são altamente subsidiadas. Os empréstimos são corrigidos pela TJLP (taxa de juros de longo prazo) que, hoje, está estabelecida em $6.5 \%$ ao ano (ver tabela para histórico). Isto significa que, hoje, os repasses do BNDES são feitos a taxas de juros menores do que a inflação que está em mais de 10\% no acumulado dos últimos 12 meses e inferiores à SELIC, taxa de juros básica da economia, que está em $14.25 \%$ ao ano. Tais práticas possuem múltiplas implicações, entre elas a dificuldade em se reduzir a taxa de juros no país, dado que boa parte dos empréstimos são feitos com juros altamente subsidiados.

Outro aspecto é que, empresas que conseguem recursos junto ao BNDES recorrem menos à outras formas de financiamento, dado que o banco oferece o menor custo de financiamento (via dívida) possível no Brasil. Bonomo et al (2015) exploram este tema com mais detalhes e mostram que, contrariamente ao propósito original, são as maiores e mais antigas companhias que conseguem recursos do BNDES, as mesmas que conseguiriam com maior facilidade captar recursos junto ao setor privado e que menos necessitam deste tipo de financiamento. Lazzarini et al (2015) apontam na mesma direção, indicando que há um desvirtuamento do propósito inicial do BNDES. Bancos de desenvolvimento deveriam suprir imperfeições de mercado que deixariam projetos lucrativos ou projetos que gerariam externalidades positivas sem financiamento por parte do setor privado, o que seria agravado em mercados de capitais menos desenvolvidos. Porém, no Brasil, os projetos financiados são aqueles das maiores empresas e melhores conectadas politicamente. Bonomo et al (2015) também mostram que empresas que conseguem empréstimos junto ao BNDES conseguem diminuir os custos de suas dívidas (dado que as taxas são subsidiadas) e consequentemente aumentam a sua lucratividade. Por outro lado, Lazzarini et al (2015) não encontram aumento no nível de investimento das firmas que recebem recursos do BNDES, corroborando a tese anterior de que são as maiores e mais antigas companhias que captam recurso junto ao banco e tais recursos são uma forma de reduzir o custo de financiamento das suas dívidas, e não necessariamente uma forma de aumentarem os investimentos. Bonomo et al (2015) sustentam a hipótese de que a crise financeira de 2008 mudou as crenças dos governantes que passaram a dar mais importância ao crédito subsidiado como impulsor do desenvolvimento nacional.

Do ponto de visto do crédito, as informações obtidas no site do Banco Central do Brasil estão disponíveis a partir de 2007. Um primeiro aspecto relevante é que, desde então, a razão da carteira de crédito sobre o PIB vem aumentando constantemente, como 
pode ser observado no Figura 3. Em 2007 o crédito total representava pouco mais de $30 \%$ do PIB, chegando a quase 54\% em 2015. Mais impressionante ainda é o aumento da participação do crédito direcionado. A participação do crédito direcionado no PIB passou de $11 \%$ para $26 \%$. Em relação ao crédito total o aumento da participação do crédito direcionado também foi considerável e as relações podem ser observadas no Figura 4. Em 2007 a representação era de $35 \%$ e passou a $49 \%$ em 2015. Neste quesito a participação do BNDES manteve-se razoavelmente constante, com ligeiras oscilações, passando de $17 \%$ da carteira de crédito total para 21\%. Inclusive, a participação do BNDES nos recursos direcionados caiu de $49 \%$ para $43 \%$. Um último dado interessante é que a carteira de crédito do BNDES passou de 5.4\% do PIB em 2007 para 11.35\% em 2015, um aumento superior a $100 \%$

A questão do aumento do forte aumento do crédito direcionado na economia brasileira é de crucial interesse para este estudo. Em Trabalho para Discussão do Banco Central (2011), Lundberg mostra que a oferta de crédito de longo prazo é feita majoritariamente pelo crédito direcionado e, no que se trata do financiamento dos investimentos de longo prazo das empresas, este mercado é dominado pelo BNDES.

Estes números apontam que o forte aumento da carteira de crédito no país desde 2007 se deu em grande parte por conta dos recursos direcionados. O crédito direcionado, conforme explicação do Banco Central do Brasil, é aquele destinado a determinados setores ou atividades, regulados em lei ou normativo. E, embora tenha aumentado consideravelmente de tamanho, a participação do BNDES nos recursos direcionados diminuiu. Isto indica que a forte expansão do crédito na economia brasileira se deu, principalmente, por conta da intervenção do governo. Tal explicação é condizente com os fatos apresentados acima. Diante da crise financeira mundial de 2008 o Governo Federal passou a interferir mais ativamente na economia, adotando medidas de estímulo ao crédito para tentar manter o consumo, o investimento e acelerar a retomada da economia. E, embora passada a crise, a mudança de trajetória das políticas econômicas se intensificaram no governo Dilma, com o surgimento da nova matriz macroeconômica e o abandono do tripé macroeconômico iniciado no governo FHC.

A importância de contextualizar o estudo é crucial para entender melhor o comportamento das empresas neste período, tanto no que tange a composição das suas dívidas que deve variar conforme o ambiente macroeconômico, como no que diz respeito às suas decisões de investimento. O objetivo desde trabalho é exatamente tentar ver a interação das decisões individuais das firmas com o ambiente macroeconômico e, para isso, num primeiro momento o estudo se concentra na composição das suas dívidas. 


\section{Literatura}

Num período de turbulência como o que estamos vivendo, é particularmente importante que economistas estudem e tentem entender melhor os dinamismos da nossa economia. Existem economistas que defendem a tese de que um importante problema na economia brasileira nas últimas décadas foi que o real valorizado frente ao dólar era prejudicial para a nossa economia. Um real menos valorizado deveria tornar a indústria nacional mais competitiva e isto teria impacto no crescimento da economia. Porém, é possível que outros aspectos ignorados ou pouco considerados nesta linha possam atenuar ou até mesmo reverter os possíveis ganhos de uma desvalorização do real.

No que tange a política monetária, existe um consenso entre os economistas de que, ao menos no curto prazo, ela pode influenciar o setor real da economia. Por outro lado, os mecanismos de transmissão da política monetária são mais controversos e menos conhecidos, fazendo com que Bernanke e Gertler (1995) o chamem de "caixa preta". A motivação dos autores é exatamente propor uma explicação para o mecanismo de transmissão da política monetária, ou seja, explicar o que acontece dentro da "caixa preta". No caso, o principal caminho apontado é pelo canal de crédito.

Empresas que desejam investir possuem duas formas de se financiarem: o financiamento externo e interno. Financiamento interno é quando uma firma usa capital próprio (lucros) para financiar os seus investimentos, o que difere do financiamento externo, que é quando firmas trazem capital externo (emissão de dívida ou de títulos) para financiarem os mesmos investimentos. Desta forma, fica visível que o investimento das empresas está relacionado à riqueza da mesma. Mesmo quando optam por financiamento externo, a quantidade de crédito que elas podem obter estará de certa forma limitada pela sua riqueza (mesmo na presença de um multiplicador). Bernanke e Gertler (1995) sugerem que efeitos patrimoniais em investimento e, consequentemente, em produto, são oriundos de imperfeições de mercado. Assimetria de informação é uma das principais explicações para as diferenças de custos entre o financiamento interno e o financiamento externo das empresas. De acordo com a teoria do canal de crédito, os efeitos da política monetária são ampliados por mudanças endógenas no chamado prêmio de financiamento externo, que é fruto de um peso morto gerado por um problema de agente-principal. Isto é, num mercado de crédito, financiadores possuem menos informação a respeito do negócio do tomador de empréstimo do que o próprio tomador de empréstimo, fazendo com que eles cobrem um maior prêmio de risco nas suas operações. Quanto maior este distanciamento, entre o que cada agente sabe, maior será o prêmio de financiamento externo. É possível inferir também que mais imperfeições de mercado resultam em mais assimetrias de informação e, consequentemente, levam a um maior prêmio de financiamento externo. 
Ainda segundo Bernanke e Gertler (1995) O chamado "canal patrimonial" consiste na ideia de que o prêmio de financiamento externo de uma firma será reduzido quanto maior for o seu patrimônio, dado que o colateral oferecido pela firma pode reduzir a questão de assimetria e informação. Isto implica que um choque negativo no patrimônio da firma aumenta o seu custo de financiamento externo, dado que a mesma terá menos colateral para dar como garantia, o que tem efeito negativo no investimento e, consequentemente, no seu produto no período seguinte. Este movimento pró-cíclico observado no "canal patrimonial" tem efeito de ampliar e expandir os efeitos da política monetária, e é por isso que os autores o chamam de "acelerador financeiro" (também detalhado em Bernanke, Gertler e Gilchrist (1999)).

No caso do canal de taxa de juros, pode existir uma discussão a respeito da amplitude de um choque, que será maior ou menor conforme o desenvolvimento do mercado de capitais da economia afetada e do grau de assimetria de informação presente na mesma. Acredita-se que em mercados menos desenvolvidos os possíveis efeitos serão ampliados. Em contrapartida, como já foi observado, não há consenso a respeito dos efeitos de uma variação cambial numa economia. Uns podem argumentar, seguindo um raciocínio dentro da lógica do modelo Mundell-Fleming, que uma desvalorização da taxa de câmbio tem um efeito expansionista numa determinada economia aberta, pois aumenta a competitividade das empresas nacionais frente as estrangeiras. Por outro lado, o (des)acelerador financeiro pode compensar este ganho de competitividade. Aghion, Bacchetta e Banerjee (2001) mostram mecanismos pelos quais uma crise cambial pode ter efeito recessivo na economia como por exemplo, mostram que países com alto endividamento em moeda estrangeira são mais susceptíveis a crises cambiais, contribuindo com a literatura dos modelos de terceira geração. Porém, efeitos contracionistas de desvalorizações cambiais também são postos em cheque por alguns autores, como Céspedes, Chang e Velasco (2002) que indicam que efeitos contracionistas de desvalorização cambial são observados apenas na presença de mercados financeiros internacionais altamente imperfeitos e endividamento em moeda estrangeira altamente expressivos.

Um passo importante para entender os efeitos recessivos de uma desvalorização cambial é estudar os chamados modelos crise de terceira geração. Em artigo publicado em 1999, Krugman desenvolve um modelo para tratar das crises cambiais que atacaram os mercados emergentes, principalmente o mercado asiático na segunda metade da década de 90. A principal motivação de Krugman e dos autores que trabalharam com modelos de terceira geração é tentar entender o mecanismo de transmissão e de propagação da crise cambial que afetou os países asiáticos na segunda metade da década de 90. Vale notar que as economias afetadas nesta crise tinham características muito divergentes dos países afetados por crises cambiais anteriores.

Até então, crises cambiais eram explicadas pelos chamados modelos de primeira e 
de segunda geração. Em trabalho publicado no The new Palgrave Dictionary of Economics(2008), Burnside, Eichenbaum e Rebelo definem precisamente o que são os modelos de primeira e segunda geração. As crises de primeira geração são causadas pela insustentabilidade da política fiscal de um determinado país. Num regime de câmbio fixo, o governo deve manter uma política monetária restritiva, o que impõe limites aos seus possíveis ganhos de senhoriagem. Quando ocorrem déficits primários recorrentes, o governo se vê obrigado a reduzir os seus ativos, se desfazendo de reservas cambiais, ou aumentando a sua dívida pública. Ambas as políticas podem surtir algum efeito, mas são insustentáveis no longo prazo. Com isso, o governo fica tentado em aumentar as suas receitas de senhoriagem, aumentando a oferta de moeda, política que é inconsistente com um regime de câmbio fixo. Em algum momento, investidores podem duvidar da capacidade do governo em honrar os seus compromissos e tais políticas resultam num ataque especulativo que marca o colapso do regime, gerando uma severa crise cambial.

Em modelos de segunda geração, governos maximizam uma função objetivo explícita que determina se e quando o governo vai abandonar o regime de câmbio fixo. Com isso, investidores podem especular a respeito do compromisso do governo em manter a paridade do câmbio, o que pode resultar numa pressão na taxa de juros. Tal pressão pressiona negativamente a economia e pode acabar resultando numa crise especulativa, provocando uma forte desvalorização do câmbio. Crises de segunda geração são um exemplo de profecias auto realizável, isto é, especulações a respeito do comprometimento do governo com a paridade do câmbio resultam, de fato, na desvalorização do mesmo.

As crises que afetaram os mercados emergentes, principalmente o mercado asiático não se enquadram nos modelos de primeira ou de segunda geração, dado que a maior turbulência se deu em países superavitários onde não havia crise de confiança com os governos, características típicas dos países trabalhados nos dois primeiros modelos. A contribuição de Krugman (1999) foi inserir um fator novo nas chamadas crises de terceira geração: o papel das firmas e as suas capacidades de investir diante de variações cambiais. Acredita-se que a o ambiente macroeconômico e o patrimônio das firmas são mutuamente influenciados uns pelos outros, ou seja, as políticas econômicas determinam e são determinadas, de certa forma, pela estrutura patrimonial das empresas.

Krugman (1999) aponta três possíveis fatores que podem levar a um colapso financeiro: endividamento alto, baixa propensão marginal a importar e alto endividamento em moeda estrangeira relativo às importações. No caso da crise asiática da segunda metade da década de noventa, observa-se que os países mais afetados eram os países nos quais as empresas possuíam alto endividamento, principalmente endividamento em moeda estrangeira, que se expandiu consideravelmente no início da década de 90 . O alto endividamento em moeda estrangeira das companhias asiáticas as expôs a maiores riscos cambiais, que propagariam efeitos recessivos de uma crise cambial para o setor real da economia. Cabe 
um paralelo com o canal patrimonial desenvolvido por Bernanke e Gertler (1995). No caso, a desvalorização cambial tem efeito negativo no patrimônio das empresas que veem os seus prêmios de financiamento externos aumentarem e, de acordo com a teoria do acelerador financeiro, os efeitos recessivos ampliam e propagam tal ciclo, agravando a crise.

Seguindo uma linha próxima a de Krugman (1999), Aghion, Bacchetta e Banerjee (2001) também desenvolvem um modelo de terceira geração para tentar explicar a crise cambial que afetou os países asiáticos na segunda metade da década de noventa. Assim como em Krugman (1999), firmas endividadas em moeda estrangeira sofrem com a deterioração das suas dívidas diante de uma desvalorização cambial. A inovação dos autores foi inserir uma rigidez nominal nos preços que tem efeito de ampliar ainda mais o efeito recessivo. No caso, firmas que não conseguem repassar as suas perdas para os seus preços veem uma deterioração ainda maior nas suas contas, reduzindo os seus lucros e, consequentemente, ampliando os efeitos recessivos da desvalorização do câmbio na economia real.

Outro aspecto importante que deve ser considerado é a questão do canal de crédito bancário. Bernanke e Gertler (1995) fizeram considerações a respeito deste canal, mas mais recentemente, Ivashina and Scharfstein (2010) estudaram o crédito bancário no mercado norte-americano durante a crise de 2008. Na ocasião, não houve apenas uma queda na demanda por crédito, mas queda na oferta de crédito também colaborou com o efeito recessivo do colapso financeiro. Numa explicação simples, bancos mais expostos ao risco tiveram uma maior perda com calotes das empresas que haviam tomado empréstimos. Assim como empresas, bancos também precisam de financiamento, e veem as suas capacidades de se financiarem deterioradas diante dos calotes. Além disso, durante uma crise, firmas e indivíduos reduzem os seus depósitos junto aos bancos. Com a capacidade de se financiarem reduzida e tendo que lidar com altos custos, bancos diminuem as suas ofertas de crédito. Isto é, a deterioração da situação patrimonial das empresas, não apenas aumenta o prêmio de financiamento externo das mesmas, como já mencionado, mas tem também um efeito perverso de diminuir o crédito disponível no mercado quando o setor bancário é afetado.

De Marco (2016 - Working Paper) também segue na mesma direção, apontando como o impacto da crise das dívidas soberanas na Europa na deterioração do patrimônio dos bancos europeus expostos a riscos soberanos afetou a oferta de crédito. O autor mostra que bancos expostos a riscos soberanos, na ocorrência de uma crise, sofrem com maiores custos para se financiarem, seja por conta de perdas diretas, como por causa de um aumento da desconfiança por parte de investidores. Uma maior dificuldade de financiamento de um banco vai resultar numa quantidade menor de crédito oferecido pelo mesmo. No contexto brasileiro analisado neste estudo, não é o caso de falar de crise de dívida soberana, pelo menos não ainda. Mas cabe um paralelo uma vez que a desvalorização do 
real frente ao dólar poderia estar prejudicando a capacidade de financiamento dos bancos brasileiros que possuem passivos em dólar frente aos seus investidores, o que pode resultar numa diminuição do crédito oferecido. O objetivo deste estudo não é modelar o setor bancário. Mas é importante apontar para outros argumentos fundamentais, presentes na literatura e que impactam no investimento das empresas, este sim, objeto de interesse do estudo.

Este trabalho se inspirou no artigo Bonomo, Martins e Pinto (2003), o artigo é sobre composição da dívida e efeitos patrimoniais de câmbio, com uma análise a nível de firma. O período de estudo é de 1990 a 2002 (com observações anuais) sendo que, até 1998, o Brasil operava num regime de câmbio fixo. Neste trabalho, a análise segue a mesma linha, com a diferença de que o se considera apenas um período com câmbio flutuante. Em Bonomo, Martins e Pinto (2003) foi encontrado um efeito patrimonial de taxa de câmbio em investimento negativo, isto é, a desvalorização do real frente ao dólar resulta em queda do investimento das empresas quando as mesmas possuem dívida em dólar. Essas dificuldades podem ser diluídas diante de outros fatores, por exemplo, empresas de bens comercializáveis podem ter um aumento de receita com uma apreciação do dólar. Outro resultado encontrado é uma relação positiva entre dívida em moeda estrangeira e investimento. Isso pode ser explicado pelo subdesenvolvimento do mercado de crédito local, principalmente no que tange crédito de longo prazo. Vale ressaltar que os resultados são robustos mesmo quando feito o controle para empresas de bens comercializáveis ou que usam insumos importados nas suas produções.

Os autores também testaram para o efeito da taxa de juros no investimento. A teste foi semelhante ao realizado com a taxa de câmbio só que, desta vez, com a taxa de juros que foi particularmente volátil no período estudado. Os resultados encontrados num primeiro momento foram significantes, mas não se sustentaram quando foi inserida a variável de dívida em moeda estrangeira, levando a interpretação de que a única dívida correlacionada com o investimento é aquela tomada em moeda estrangeira.

Outro estudo que serviu de inspiração foi Janot et al (2008), um trabalho para discussão do Banco Central que estudou a crise cambial de 2002, com uma base de dados englobando o período de 2000 a 2004. Nesse período o real teve uma desvalorização nominal de $53 \%$ frente ao dólar, contra uma desvalorização real de $71 \%$ no período deste estudo. No estudo, os autores comparam empresas com descasamentos cambiais de suas dívidas e empresas sem descasamentos cambiais. A inovação do trabalho em relação aos anteriores é a inserção de dados obtidos nas notas explicativas das empresas que apontavam para possíveis descasamentos cambiais. Tais informações não são obtidas nos balanços divulgados e são de mais difícil acesso. Outro aspecto interessante do trabalho é que ele se concentra num período amostral relativamente restrito, em torno da crise cambial ocorrida no Brasil em 2002. No seu período amostral, o real sofreu uma forte desvalorização de forma rápida 
e depois foi retornando aos patamares anteriores. Neste estudo, a desvalorização do real se deu de forma mais suave, porém contínua, inclusive continua ocorrendo no termino do período amostral. Os resultados obtidos por Janot et al (2008) apontam que empresas com descasamento cambial observam uma forte queda dos seus investimentos frente a empresas sem descasamento cambial, o mesmo valendo inclusive para empresas exportadoras que possuem as suas receitas em dólar. Os resultados encontrados são condizentes com os apresentados em Bonomo, Martins e Pinto (2003), isto é, empresas endividadas em dólar sofrem perdas patrimoniais quando há uma desvalorização do real e isto afeita as suas capacidades de investimento.

Bleakley e Cowan (2002) realizaram um estudo na mesma linha, com um painel contendo mais de 500 empresas não financeiras em 10 países da américa latina: Argentina, Bolívia, Brasil, Chile, Colômbia, Costa Rica, México, Peru, Uruguai e Venezuela, dentre as quais mais de 50\% eram empresas brasileiras. Em Bonomo, Martins e Pinto (2003) e Janot (2006), assim como neste estudo, são consideradas apenas empresas brasileiras. Olhar para empresas de apenas um país permite controlar para especificidades locais, como o cenário macroeconômico. Bleakley e Cowan (2002) concluem que possuir dívida em moeda não estaria associado a redução do investimento diante de uma desvalorização cambial, pelo contrário, eles apontam que tais empresas tendem a aumentar os seus investimentos. Uma possível explicação para isso, segundo os autores, é que empresas com endividamento estrangeiro costumam ser aquelas que mais se beneficiam diante de desvalorizações cambiais, como por exemplo, empresas exportadoras. Tais resultados vão de encontro com aqueles apresentados nos outros dois estudos mencionados. Além da inserção de outros países além do Brasil, uma das possíveis explicações para tais diferenças nos resultados é o período amostral. Em Bleakley e Cowan (2002) as observações se encerram em 1999, ou seja, possuem menos de 2 anos de observações com câmbio flutuante, em Bonomo, Martins e Pinto (2003) o período em câmbio flutuante foi maior. Neste trabalho, assim como em de Janot et al (2008), todo o período amostral é de câmbio flutuante. 


\section{Composição da Dívida}

\subsection{Motivação}

Um primeiro passo no sentido de entender efeitos patrimoniais de câmbio é estudar a composição da dívida das empresas. Com a base de dados elaborada, é possível distinguir dois aspectos importantes das dívidas corporativas que serão usados: dívida tomada em moeda estrangeira (considera-se dólar) e dívida de longo prazo (endividamento com vencimento superior a 1 ano). Outros dados, como dívida por arrendamento financeiro e endividamento via debêntures também foram coletados, mas não serão analisados separadamente neste estudo. As debêntures são títulos de dívida corporativa, nos moldes da dívida pública. Vale apenas observar que, até 2005, o mercado de debêntures no Brasil era consideravelmente pequeno e vem crescendo desde então, encolhendo de tamanho apenas durante a crise de 2008 e recentemente, em 2015, por conta da queda de atividade no país. Neste estudo, as debêntures serão consideradas como dívida em moeda nacional de curto ou longo prazo, dependendo do vencimento dos títulos.

A composição da dívida de uma empresa pode refletir diretamente no seu resultado. A possibilidade de se endividar é importante para manter ou ampliar a atividade de uma empresa que necessita mais do que a a sua capacidade interna de se financiar. $\mathrm{O}$ financiamento interno é uma fonte importante de financiamento para as empresas nacionais por causa do baixo desenvolvimento do mercado de capitais doméstico, porém, após a estabilização da moeda e o desenvolvimento constante do mercado financeiro nacional, as firmas cada vez mais fazem uso de financiamento externo, tanto no mercado doméstico como fora do país.

Empresas fazem uso de financiamento externo devem tentar casar os vencimentos e os riscos das suas dívidas com os retornos esperados dos seus investimentos. Por exemplo, bens de capital deveriam, idealmente, ser financiados com empréstimos de longo prazo. No Brasil, com um agente do tamanho do BNDES alimentando o mercado de crédito de longo prazo com taxas de juros altamente subsidiadas, empresas têm o incentivo de usar esta fonte de crédito sempre que possível. O financiamento através do BNDES dificilmente é menos interessante do que qualquer outra fonte de financiamento. Portanto, este tipo de empréstimo muitas vezes é utilizado como forma de diminuir os custos das dívidas das empresas, e não como recursos a serem investidos nas suas atividades, o que pode gerar distorções.

Do ponto de vista do crédito em moeda estrangeira, empresas endividadas desta forma devem buscar se proteger de possíveis variações cambiais que impactam no custo da 
dívida, seja com um hedge financeiro, seja com um hedge natural, isto é, receitas também em moeda estrangeira. Tal aspecto é exploradoanot que, entrando nas notas explicativas das empresas, mostra que empresas com hedge cambial sofreram menos diante da crise cambial ocorrida em 2002. Como mencionado em Bonomo, Martins e Pinto (2003), as altas taxas de juros praticadas no Brasil implicam que, em muitos casos, empresas com acesso a financiamento estrangeiro optam por este tipo de investimento mesmo com o maior risco cambial. Muitas vezes, é mais barato contrair um endividamento em moeda estrangeira e usar algum mecanismo de hedge do que contratar dívida no país. Porém, deve-se ressaltar que, embora o Brasil tenha se desenvolvido neste aspecto, o acesso ao crédito em moeda estrangeira ainda não é acessível para todas as empresas.

Em mercados de capitais desenvolvidos e com poucas fricções, não deveríamos esperar muitas diferenças na composição da dívida de empresas grandes e pequenas, dado que não haveria prêmio de custo de financiamento externo. Mas, conforme sugere a literatura, imperfeições levam a maiores custos de financiamento externo, dificultando tanto o acesso ao crédito de maior prazo quanto o financiamento estrangeiro. No Brasil, tal situação é particularmente válida. Poucas são as empresas brasileiras com endividamento em moeda estrangeira. Isto possui várias explicações, as principais sendo que são poucas as empresas nacionais listadas em bolsas de valores estrangeiras. Outro aspecto é a avaliação de crédito do país e das suas empresas. No período observado, o Brasil obteve o chamado grau de investimento entre os anos 2008 e 2015, nos outros anos os títulos brasileiros são considerados de nível especulativo, sendo que, boa parte das companhias nacionais não chegaram a ter o grau de investimento em momento algum. Muitos investidores internacionais, principalmente fundos de pensão, possuem normas rígidas quanto à qualidade dos seus títulos, diminuindo ou cortando o investimento conforme a redução da avaliação de crédito.

O mercado de crédito de longo prazo é outro setor atingido pelas imperfeições de mercado presentes na economia brasileira. Este mercado é particularmente deficiente no país, com poucos agentes participando no lado da oferta, o maior dele sendo o BNDES (no que diz respeito ao crédito direcionado para investimento). Como já mencionado, o propósito de um banco de desenvolvimento, a priori, é prover financiamento para projetos com externalidades positivas e / ou para aqueles que não conseguem financiamento (ou conseguem, mas com custos impraticáveis) no setor privado. Isto não ocorre com o BNDES, que provê mais financiamento para grandes empresas, com taxas de juros altamente subsidiadas. É preciso ressaltar também que, questões ligadas à risco de inadimplência, ou até mesmo risco regulatório são fatores que, de certa forma, desestimulam a participação do setor privado na oferta de crédito. 


\subsection{Estratégia}

Diante disso, é importante estudar como é a estrutura das dívidas corporativas. Este trabalho vai focar apenas nas questões dos prazos das dívidas, decomposto em curto e longo prazo, e nas moedas (nacional ou estrangeira). Para tanto, seguiu-se o modelo proposto por Bonomo, Martins e Pinto (2003) e com base nos dados coletados, pode-se analisar a seguinte equação para estudar a estrutura das dívidas das empresas e os seus fatores determinantes:

$\mathrm{r}_{i, t}=c+\alpha m_{t} \cdot f_{i, t}+\beta \cdot f_{i, t}+y_{t}+e_{i, t}$

Num primeiro momento $r_{i, t}$ irá representar a razão da dívida em moeda estrangeira sobre a dívida total, $m_{t}$ será a volatilidade da taxa real de câmbio, $f_{i, t}$ é um vetor com as características das firmas variantes no tempo (tamanho, tomado como log do capital). Num segundo momento $r_{i, t}$ representará a razão da dívida de longo prazo sobre a dívida total e $m_{t}$ será a volatilidade da taxa de inflação. A volatilidade, em ambos os casos, representa um maior risco para as empresas, isto é, uma volatilidade maior é sinal de maior risco. Em ambas as estimações, assim como para todas que virão em seguida no trabalho, são inseridas dummies de período, mas que estão ocultadas por questões de espaço.

Diante de mercados de capitais altamente imperfeitos, como é o caso brasileiro, a composição das dívidas das empresas se dá mais pelo lado da oferta do que pelo lado da demanda de crédito. Isto é, a disponibilidade e os termos exigidos para os contratos de crédito, embora sempre importantes, são ainda mais determinantes do caso da economia brasileira. Isto vale tanto para o crédito de longo prazo quanto para o crédito em moeda estrangeira, altamente ligado à liquidez do mercado internacional.

Por ambas as dívidas, em moeda estrangeira e de longo prazo, serem frações da dívida total, a variável $r_{i, t}$, nos dois casos, necessariamente se encontra entre 0 e 1 . Observa-se também que as variáveis são truncadas (não são observáveis fora deste intervalo) com pontos de acumulação nos limites, isto é, uma quantia significativa das observações encontra-se nos limites, superior e inferior. Portanto, estimar a equação pelo método convencional, OLS, pode gerar estimadores viesados e inconsistentes. Ao incluir as observações truncadas, o modelo OLS subestima o intercepto da curva e sobrestima a sua inclinação. Ao não incluir as observações truncadas, o efeito é inverso, isto é, sobrestimase o intercepto e subestima-se a inclinação. O grau do viés em ambos os casos aumenta conforme aumenta o número de variáveis censuradas. O modelo Tobit (Tobin, 1958) assume que existe uma variável oculta por baixo da variável dependente $\left(r_{i, t}\right)$. As variáveis seriam iguais quando a variável oculta é diferente de zero. O modelo tobit é um modelo não-linear que usa o método da máxima verossimilhança decomposto em duas partes: para as observações não censuradas usa-se uma função densidade de probabilidade, e para as 
variáveis censuradas é a função distribuição acumulada.

Nesta estimação foram consideradas apenas as observações referentes ao último trimestre de cada ano e não todos os trimestres, no período em que o país viveu sob regime de câmbio flutuante, isto é, os últimos trimestres de cada ano entre 1999 e 2015.

\subsection{Resultados}

Portanto, a primeira estimação da equação acima é uma tobit que capta como a volatilidade do câmbio interagida com o tamanho da empresa e o próprio tamanho da empresa (capital instalado, isto é, ativo imobilizado) vão impactar na razão da dívida em moeda estrangeira sobre a dívida total. Vale ressaltar que, neste caso, usa-se a volatilidade do câmbio, e não a sua taxa de variação. A ideia é que volatilidade cambial gera incerteza, que atrapalha o planejamento da empresa, resultando numa aversão à ela.

Os resultados encontrados estão apresentados na Tabela 1. Observa-se que o coeficiente associado ao tamanho da empresa é positivo e significante a nível de $1 \%$ e aquele associado à variável de interação da dívida em moeda estrangeira com a volatilidade do câmbio é negativo mas não significante. Isto significa que, empresas maiores conseguem mais financiamento em moeda estrangeira. O resultado vai de acordo com aquele encontrado em Bonomo, Martins e Pinto (2003) no que diz respeito ao coeficiente relacionado ao tamanho da empresa, mas, no estudo citado, os autores encontraram um coeficiente negativo e significante para a interação da dívida em moeda estrangeira e a volatilidade do câmbio. Como mencionado, em mercados de capitais altamente imperfeitos, a composição da dívida das empresas tende a ser ditada mais pelo lado da oferta de crédito do que pelo lado da demanda, afirmativa válida, inclusive, no que diz respeito ao financiamento em moeda estrangeira oferecido por credores internacionais. Portanto, espera-se que empresas maiores consigam mais financiamento em moeda estrangeira do que empresas menores, dado que, normalmente, apresentam menores riscos por conseguirem oferecer um maior colateral. Esta interpretação vai de acordo com a escolha de um modelo tobit para esta equação. Isto significa que empresas menores, muitas vezes, não se financiam em moeda estrangeira não por não o desejarem, mas por não terem acesso ao mercado internacional. Ou seja, existe uma variável oculta por trás de $r_{i, t}$ que é igual a zero, mas tomaria o mesmo valor de $r_{i, t}$ caso fosse diferente de zero.

Adicionalmente, foram inseridas variáveis dummies para empresas que possuem ADR, para empresas de bens comercializáveis e para empresas que, no período observado, possuem um ativo imobilizado superior à média dos ativos de todas as empresas no mesmo período. Como já argumentado, pode-se esperar que empresas com ADR na bolsa de Nova Iorque tenham uma melhor gestão cambial e possuam um maior acesso ao mercado internacional, logo, isto estaria afetando o resultado encontrado. Empresas de 
bens comercializáveis podem, eventualmente, ganhar com variação cambial, o que também pode impactar no resultado. Os resultados são apresentados na coluna seguinte da Tabela 1. Os coeficientes para as dummies de ADR e de bens comercializáveis, como esperado, foram positivas e significantes à nível de $1 \%$. A dummy para tamanho do ativo se mostrou negativa e insignificante. Espera-se que empresas com ADR consigam mais financiamento externo, portanto a razão $r_{i, t}$, de fato, deve aumentar na presença de ADR, e empresas de bens comercializáveis possuem um hedge natural em potencial, dado que as suas receitas podem também variar com a volatilidade do câmbio, reduzindo a incerteza associada a volatilidade cambial. Como pode-se observar, a inserção das duas variáveis pouco altera os resultados apresentados anteriormente e a interpretação segue a mesma.

Com isso, pode-se passar para a segunda estimativa de $r_{i, t}$. Agora, a variável vai representar a razão da dívida de longo prazo sobre a dívida total, estimada em função do tamanho da empresa (sempre o ativo imobilizado) e da interação do tamanho da empresa com a volatilidade da inflação.

Os resultados encontrados são apresentados na Tabela 2. Aqui, mais uma vez, o coeficiente relacionado ao tamanho da empresa é positivo e significante a nível de $1 \%$, e a variável de interação de inflação com o tamanho da empresa é negativo e insignificante. Isto é, assim como no caso do crédito em moeda estrangeira, empresas maiores têm mais acesso à crédito de longo prazo. Deve-se destacar que o resultado difere do encontrado em Bonomo, Martins e Pinto (2003), que encontraram um coeficiente para o tamanho da empresa negativo. No artigo, os autores explicam o valor negativo para o tamanho da empresa como uma possível intervenção do BNDES no mercado de crédito de longo prazo. Segundo eles, naquele momento, o banco poderia estar subsidiando mais financiamento de longo prazo para empresas menores, o que seria, de fato, o propósito de um banco de desenvolvimento. Aqui, a explicação para a mudança do sinal, que agora é positivo e significativo é exatamente a oposta. O BNDES pode, no passado, ter fornecido mais crédito de longo prazo para empresas menores. Porém, tal prática não ocorre mais no presente, uma vez que o banco financia projetos de grandes empresas.

Nesta estimação tomou-se o mesmo cuidado da anterior. Foram acrescidas variáveis dummies para ADR para bens comercializáveis e dummies para o tamanho do ativo. O valor positivo para ADR indica que empresas com ADR na bolsa de Nova Iorque conseguem mais crédito de longo prazo, o que é esperado, pelos mesmos fatores que as levam a conseguir mais crédito em moeda estrangeira. Por suas vez, não existe uma explicação para o sinal negativo e significante a nível de $5 \%$ para a dummy de bens comercializáveis. O sinal esperado seria positivo, uma vez que espera-se que firmas de bens comercializáveis, em geral, realizem mais investimentos de longo prazo, portanto, tomem mais financiamentos de longo prazo. Porém, mais uma vez, mesmo acrescidos estes controles, os resultados continuam consistentes com os obtidos anteriormente. 


\section{Efeitos Patrimoniais de Câmbio}

\subsection{Motivação}

Após a estabilização da moeda com o Plano Real, o país passou mais de 4 anos sob regime de câmbio fixo. Após ser reeleito em 1998, uma das primeiras medidas que o presidente Fernando Henrique Cardoso tomou em 1999 foi mudar de regime e migrar para um sistema de câmbio flutuante. Embora muitos critiquem e apontem que há uma forte intervenção do Banco Central no mercado de câmbio, considera-se que o câmbio flutue livremente no país desde 1999. Portanto, esta seção, assim como a anterior, considera os anos no qual o país viveu em período de câmbio flutuante, considerando os balanços divulgados no último trimestre de cada ano. Como já mencionado, neste período o país passou por alguns momentos de forte turbulência cambial, tornando a análise particularmente interessante.

Uma vez tendo analisado a composição da dívida das empresas brasileiras e os seus fatores determinantes, pode-se seguir para a análise do efeito patrimonial do câmbio. A ideia é ver como flutuações cambiais vão impactar no patrimônio das empresas e quais as suas consequências. O mecanismo segue aquele explicado na literatura: empresas endividadas em moeda estrangeira, dependendo do grau de descasamento, aumentam o custo de rolagem das suas dívidas, reduzindo os seus lucros e os seus investimentos, que resultam numa maior dificuldade de financiamento e numa queda ainda maior do próprio investimento.

\subsection{Estratégia}

O primeiro passo tomado é o de estimar uma equação simples que pode testar diretamente o efeito da variação cambial na taxa de investimento. A equação é a seguinte:

$$
\text { invest }_{i, t}=\text { ainvest }_{i, t-1}+\gamma \frac{D_{i, t-1}^{*}}{K_{i, t-1}} \Delta \ln (R E R)_{t}+\delta \frac{D_{i, t-1}^{*}}{K_{i, t-1}}+\varphi \frac{D_{i, t-1}}{K_{i, t-1}}+\eta_{t}+\mu_{i}+\epsilon_{i, t}
$$

Nesta equação, a variável invest representa o investimento. O investimento é tomado a partir da taxa de variação do ativo imobilizado acrescido da depreciação ocorrida no período. Esta variável também se encontra variável dependente defasada, $D_{i, t-1}^{*}$ representa a dívida em moeda estrangeira, que também é interagida com a taxa de variação da taxa de câmbio real $(R E R), D_{i, t-1}$ representa o total da dívida, $\eta_{t}$ são as dummies de período (trimestres) e $\mu_{i, t}$ são características individuais das firmas (bens comercializáveis, ADR, tamanho, etc.). 


\subsection{Resultados}

Num primeiro momento estima-se a equação acima sem a variável defasada de investimento. Os resultados estão apresentados nas quatro primeiras colunas da Tabela 3. A primeira coluna é uma estimação OLS simples, seguida de uma OLS com efeitos fixos e do GMM, em sistema e em diferenças. Nas duas primeiras colunas pode-se notar que o coeficiente associado à variável de interação entre endividamento em moeda estrangeira e variação da taxa de câmbio é negativo e significante a nível de $1 \%$. As colunas 3 e 4 não são de muito interessantes, uma vez que a metodologia GMM é mais adequada na presença de um componente dinâmico, que será explicado mais a frente.

Outras variáveis que são consideradas são as dummies para ADR, para bens comercializáveis. É criada um terceira dummy também, d_imob, que assume valor 1 caso o ativo imobilizado da empresa seja maior do que a média dos ativos totais no mesmo período e 0 caso contrário.

Nas colunas de 5 a 8 da mesma tabela são apresentados os resultados com a inserção da variável dependente defasada. Nas colunas 5 e 6 temos, respectivamente, o OLS e o OLS com efeitos fixos. A variável de investimento defasada apresenta um coeficiente positivo, conforme poderia-se esperar e significante a nível de 1\%. Por sua vez, o coeficiente associado à variável de interação entre o endividamento em moeda estrangeira e a variação cambial é negativo e significante a nível de $1 \%$.

Em modelos dinâmicos, a própria estrutura do modelo implica em estimações viesadas quando estima-se com um OLS. Considere o seguinte modelo dinâmico simples:

$$
\mathrm{y}_{i, t}=\gamma y_{i, t-1}+x_{i, t}^{\prime} \beta+u_{i, t} \text { e } \mathrm{u}_{i, t}=\mu_{i}+\varepsilon_{i, t}
$$

Onde a correlação entre $y_{i, t-1}$ e $\mu_{i}$ estará resultando numa estimação viesada dos coeficientes da equação sugerida.

Portanto, na equação sugerida para avaliar os efeitos das variações cambiais no investimento das empresas, o componente constante no tempo de $\varepsilon_{i, t}$ está correlacionado com invest $_{i, t-1}$, implicando numa estimação viesada dos coeficientes.

Uma primeira solução para este problema foi apresentada por Anderson e Hsiao (1981), que sugerem usar o modelo em primeiras diferenças, o que permite remover o componente individual do erro $\mu_{i}$, usando a variável dependente defasada em dois períodos como instrumento para o termo autorregressivo. Este método pode levar a estimações consistentes mas não necessariamente eficientes dos parâmetros do modelo. Arellano e Bond (1991) sugerem um método dos momentos generalizados (GMM) para abordar o mesmo problema que é mais eficiente do que o colocado por Anderson e Hsiao (1981).

Em Arellano e Bond (1991) são postos um certo número de condições iniciais. Primeiramente, o componente individual do erro não variante no tempo $\left(\mu_{i}\right)$ não deve 
estar correlacionado com $\varepsilon_{i, t}$. Os distúrbios $\varepsilon_{i, t}$ não devem apresentar autocorrelação serial, nem correlação com $y_{i, t}$ e $x_{i, t}$. Dadas estas condições, o estimador GMM apresentado por Arellano e Bond permite estimar os parâmetros sem o viés decorrente do componente dinâmico. Toma-se então, assim como em Anderson e Hsiao (1981) a primeira diferença que permite eliminar efeitos fixos individuais e, além disso, para ganhar em eficiência, fazse uso de maiores defasagens das variáveis. Este primeiro estimador baseado em Arellano e Bond (1991) é chamado de GMM em diferenças.

Portanto, o passo seguinte no sentido de entender efeitos patrimoniais de câmbio foi estimar a equação proposta adotando o modelo GMM em diferenças. Os resultados são apresentados na coluna 7 da Tabela 3. Observa-se que, desta vez, o único coeficiente significante encontrado foi para a variável de investimento defasada, que é significante a nível de $1 \%$.

Em sequência, na coluna 8 da Tabela 3 são apresentados os resultados para a estimação da mesma equação com o GMM em sistema. O GMM em sistema, assim como aquele em diferenças, usa as variáveis em primeiras diferenças, mas usa também as variáveis em nível, o que torna o estimador mais eficiente. Os resultados encontrados são semelhantes aos do GMM em sistema, que apresenta apenas a variável de investimento defasada como positiva e significante.

Os resultados apresentados levam a concluir que o efeito patrimonial de câmbio, na verdade, são insignificantes, contrariamente ao que foi apresentado nas primeiras estimações. Portanto, o passo seguinte do estudo foi investigar possíveis explicações para este resultado insignificante.

Na Tabela 4 também estão apresentados os resultados da mesma equação, mas com dados trimestrais apenas a partir do último trimestre de 2010. Vale ressaltar que em tal ano houve uma reforma contábil importante que acarretou a uma mudança na disposição dos dados divulgados. O resultado difere do anterior no que tange ao efeito patrimonial de câmbio apresentado na última coluna, que ficou positivo e altamente significante, o que é inesperado e pode ser analisado com mais detalhes em pesquisas futuras. 


\section{Análise Setorial}

Um primeiro passo no sentido de entender o resultado anterior é observar quais são as empresas endividadas em moeda estrangeira. Na Tabela 5 é possível notar que, em 1999, as empresas com endividamento em moeda estrangeira representavam $60.7 \%$ do total de empresas. Tal proporção caiu para 33.1\% em 2015. Nota-se, inclusive, uma queda muito acentuada a partir de 2009, que pode ser explicada por dois fatores: a crise financeira de 2008 fazendo com que empresas fiquem avessas à endividamento em moeda estrangeira, e o aumento da participação do BNDES no mercado de crédito.

Na mesma tabela é possível ver também que, das empresas endividadas em moeda estrangeira, mais de $60 \%$ são empresas de bens comercializáveis, que, pela natureza de seus produtos, possuem um hedge natural para flutuações cambiais. Com isso, empresas endividadas em moeda estrangeira sem este hedge, representam uma parcela pequena do total de empresas da amostra.

Com isso, para poder controlar para questões de exportações e importações, foram coletados os dados a nível de setor (pois não são disponibilizados a nível de firma) na Fundação Centro de Estudos do Comércio Exterior (FUNCEX). Com estes dados, é possível estimar a mesma equação da seção acima, mas agora fazendo um controle setorial para exportações e importações.

Os resultados estão apresentados na Tabela 6. Aqui, o coeficiente associado à variável de investimento continua positivo e significante a nível de $1 \%$ e a variável interativa entre endividamento em moeda estrangeira e variação cambial é negativa e altamente significante, apontando que, controladas as exportações e importações por setores, o efeito patrimonial da variação cambial é negativo e forte. Importante ressaltar também que o coeficiente associado a variável defasada de endividamento em moeda estrangeira também é positivo e significante a nível de 1\%. Isto aponta que endividamento em moeda estrangeira está associado à maiores taxas de investimento. 


\section{Efeitos Patrimoniais em Mercados de Ca- pitais Imperfeitos}

Bernanke e Gertler (1995) mostram que, em mercados de capitais perfeitos, não há diferenças entre os custos de financiamento internos e externos. Isto implica que as decisões de investimento das firmas não seriam baseadas por questões financeiras, mas sim pela atratividade dos projetos. Efeitos patrimoniais são apenas observados quando há uma diferença nestes custos, causadas pelas imperfeições dos mercados de capitais.

Em Hayashi (1982) é apresentado um modelo para o chamado Q de Tobin, que é a razão entre o valor de mercado do investimento e o valor de mercado de reposição do capital. Quando esta razão é superior a 1, é interessante para as firmas investirem, ocorrendo o oposto quando a razão é inferior a 1. Efeitos patrimoniais aumentam o custo de reposição do capital, reduzindo a razão Q, o que deveria reduzir o investimento.

É difícil estimar empiricamente o Q de Tobin conforme definido acima. Por isso, em Hayashi (1982) é sugerido um modelo alternativo para a estimação do Q de Tobin, chamado de $\mathrm{Q}$ de Tobin médio, que, assumidas certas hipóteses, é equivalente ao Q de Tobin marginal. Portanto, neste trabalho, foi estimado o Q de Tobin médio. No numerador foi colocada a soma do valor de mercado da firma e a sua dívida total líquida, e no denominador está o patrimônio líquido somado da dívida total líquida.

O Q de Tobin possui a vantagem de englobar todos os fatores que afetam a lucratividade de um investimento. Isto é, para este estudo, o Q de Tobin é um controle mais potente do que exportações e importações, por exemplo. Aqui, se uma desvalorização do real frente ao dólar aumenta oportunidades de investimento para uma firma exportadora, esta firma verá o seu Q de Tobin aumentar. Por outro lado, uma firma endividada em moeda estrangeira vê o seu custo de reposição de capital aumentar, o que faz com que a sua razão Q diminua. Com isso, estima-se a seguinte equação:

$$
\text { invest }_{i, t}=\text { ainvest }_{i, t-1}+\lambda q_{i, t}+\theta \frac{C F_{i, t}}{K_{i, t-1}}+\gamma \frac{D_{i, t-1}^{*}}{K_{i, t-1}} \Delta \ln (R E R)_{t}+\mu_{i}+\epsilon_{i, t}
$$

Aqui também foi acrescentada a variável CF, representando o fluxo de caixa. Assim como no primeiro exercício para estimar efeitos patrimoniais de câmbio, foi estimado um GMM em sistema, e os resultados estão apresentados na Tabela 7.

O que se pode observar é que a única variável que se mostrou significante (a nível de $1 \%$ ) foi a taxa de investimento defasada, todas as outras não foram significantes, o que vai de encontro com o resultado anterior que sugeria que havia efeitos patrimoniais de câmbio, quando controlados para exportações e importações. 


\section{Conclusão}

Neste trabalho, não foi possível apontar efeitos patrimoniais de variações cambiais significantes quando tomado o conjunto das empresas listadas na bolsa de valores de São Paulo entre 1999 e 2015. Os resultados encontrados inicialmente, de efeitos patrimoniais negativos e significantes tornaram-se insignificantes quando estimados pelo GMM, que é o método mais adequado em modelos dinâmicos. Ao serem inseridos controles de exportação e importação a nível de indústria, tais resultados passaram a ser negativos e altamente significantes, o que estaria apontando que, eliminados os efeitos de exportação e importação, há um efeito patrimonial importante. Porém, os efeitos encontrados voltaram a se tornar insignificantes quando usado o $\mathrm{Q}$ de Tobin que, como apontado, é considerado o melhor controle possível. De acordo com os resultados obtidos, pode-se dizer que, tomando o conjunto de empresas brasileiras, a questão do câmbio não é a mais importante na determinação do investimento das empresas.

Uma explicação para este resultado, como foi apontado, é a queda do número de empresas endividadas em moeda estrangeira, assim como o perfil das empresas que se financiam desta forma, dado que $60 \%$ delas são de bens comercializáveis. Pode ser interessante tentar avaliar os efeitos patrimoniais de câmbio apenas para empresas de bens não comercializáveis. Um ponto importante que não foi considerado neste estudo mas que pode ser estudado em análise futura é a questão do hedge das empresas. Com o desenvolvimento dos mercados de capitais, existem diversas formas das empresas se protegerem de crises cambiais. Tais informações são encontradas nas notas explicativas divulgadas pelas empresas e podem ser levantadas. Outro aspecto interessante que pode ser analisado é a questão do BNDES. Poderia-se estudar mais a fundo o perfil das empresas que conseguem se financiar pelo BNDES e criar um controle para isto, dado que empresas podem estar trocando financiamento de longo prazo em moeda estrangeira por financiamento do banco de desenvolvimento. 


\section{Referências}

Aghion, P., Bacchetta, P. and Banerjee, A. 2001 "Currency Crises and Monetary Policy in an Economy with Credit Constraints". European Economic Review. 45 (7): 1121-1150.

Arellano, M. and Bond, S. 1991 "Some tests of specification for panel data: Monte Carlo evidence and an application to employment equations", Review of Economic Studies 58: 277-97.

Bernanke, B. and Gertler, M. 1995 "Inside the Black Box: The Credit Channel of Monetary Policy Transmission. "Journal of Economic Perspectives 9: 27-48

Bernanke, B., Gertler, M. and Gilchrist, S. 1999 "The Financial Accelerator in a Quantitative Business Cycle Framework"Handook of Macroeconomics, vol. 1c, New York: Elsevier Science Ltd

Bleakley, H. and Cowan, K. 2002 "Corporate dollar debt and devaluations: Much ado about nothing?". Mimeo. MIT.

Bonomo, M.A., Brito, R., Martins, B. 2015 "The after crisis government-driven credit expansion in Brazil: a firm level analysis"Journal of International Money and Finance (2015), http://dx.doi.org/10.1016/j.jimonfin.2015.02.017

Bonomo, M.A., Martins, B., Pinto, R. 2003 "Debt Composition and Exchange Rate Balance Sheet Effects in Brazil: A Firm Level Analysis". Emergin Markets Review v. 4, p. 368-396, 2003

Céspedes, L.F., Chang, R., Velasco, A. 2003 "IS-LM-BP in the Pampas", IMF Staff Papers Vol. 50, Special Issue

De Marco, F. 2016 "Bank Lending and the European Sovereign Debt Crisis"(February 15, 2016). Available at SSRN: http://ssrn.com/abstract=2673967 or http://dx.doi.org/10.2139/ssrn.2 Doidge, C., Karolyi, G.A., Stulz, R. 2004 "Why are foreign firms listed in the U.S. worth more?" Journal of Financial Economics 71: 205-238, 2004.

Hayashi, F. 1982 "Tobin's Marginal q and Average q: A Neoclassical Interpretation. "Econometrica 50: 213-224.

Ivashina, V. and Scharfstein, D. 2010 "Bank lending during the financial crisis of 2008", Journal of Finalncial Economics 97 (2010) 319-338

Janot, M., Garcia, M. and Novaes, W. 2008 "Balance Sheet Effects in Currency Crises: Evidence from Brazil.", Trabalho para Discussão 162 p. 1-46, Banco Central do Brasil.

Janot, M., Novaes, W. 2009 "Ganhos da Globalização do Capital Acionário em Crises Cambiais"Trabalho para Discussão 183 p. 1-51, Banco Central do Brasil

Lazzarini, S. G., Musacchio, A., Bandeira-de-Mello, R., Marcon, R. 2015 "What 
do development banks do? Evidence from BNDES 2002 - 2009"Word Dev. 66, 237-253 Lundberg, E.L. 2011 "Bancos Oficiais e Crédito Direcionado - O que diferencia o mercado de crédito brasileiro?" Trabalho para Discussão 258 p. 1-39, Banco Central do Brasil. 
Anexos 


\section{ANEXO A - Gráficos}

Figura 1: Evolução das Taxas de Juros e de Inflação

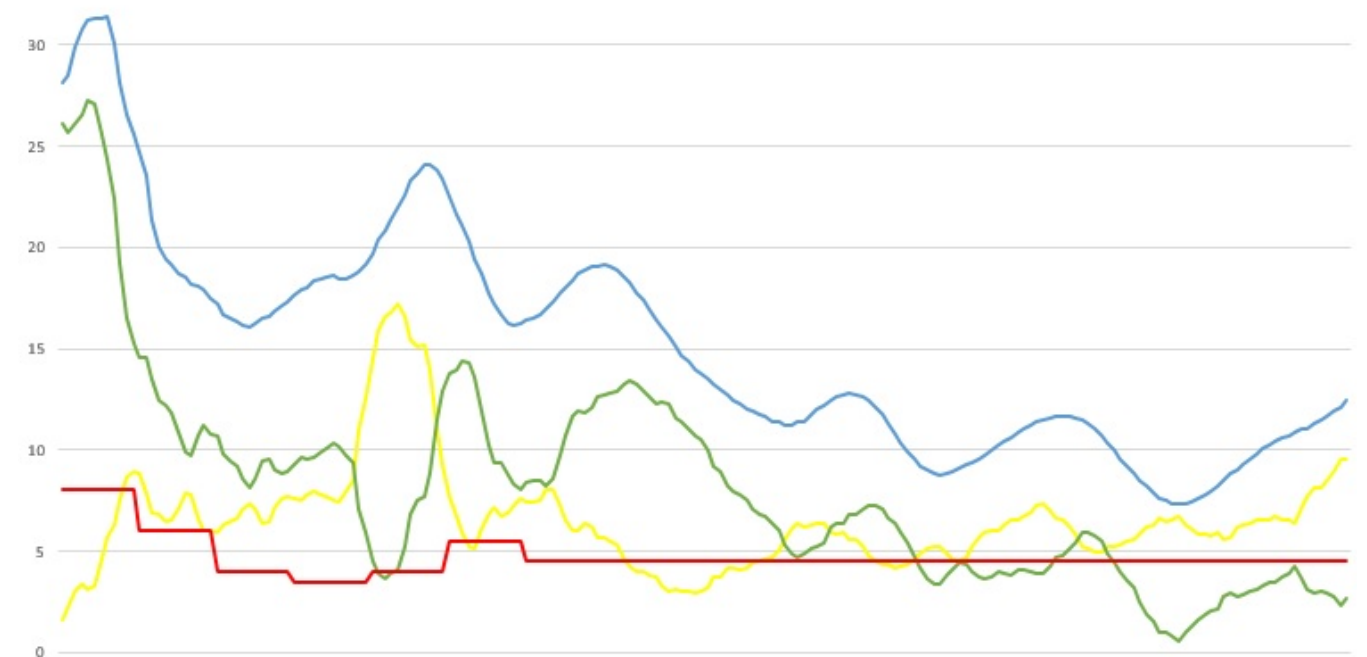

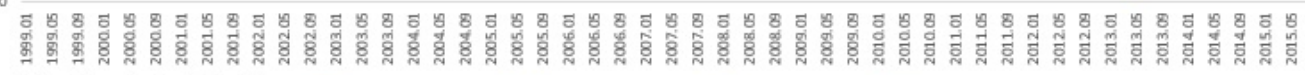

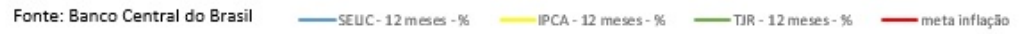

Figura 2: Evolução da Taxa de Câmbio

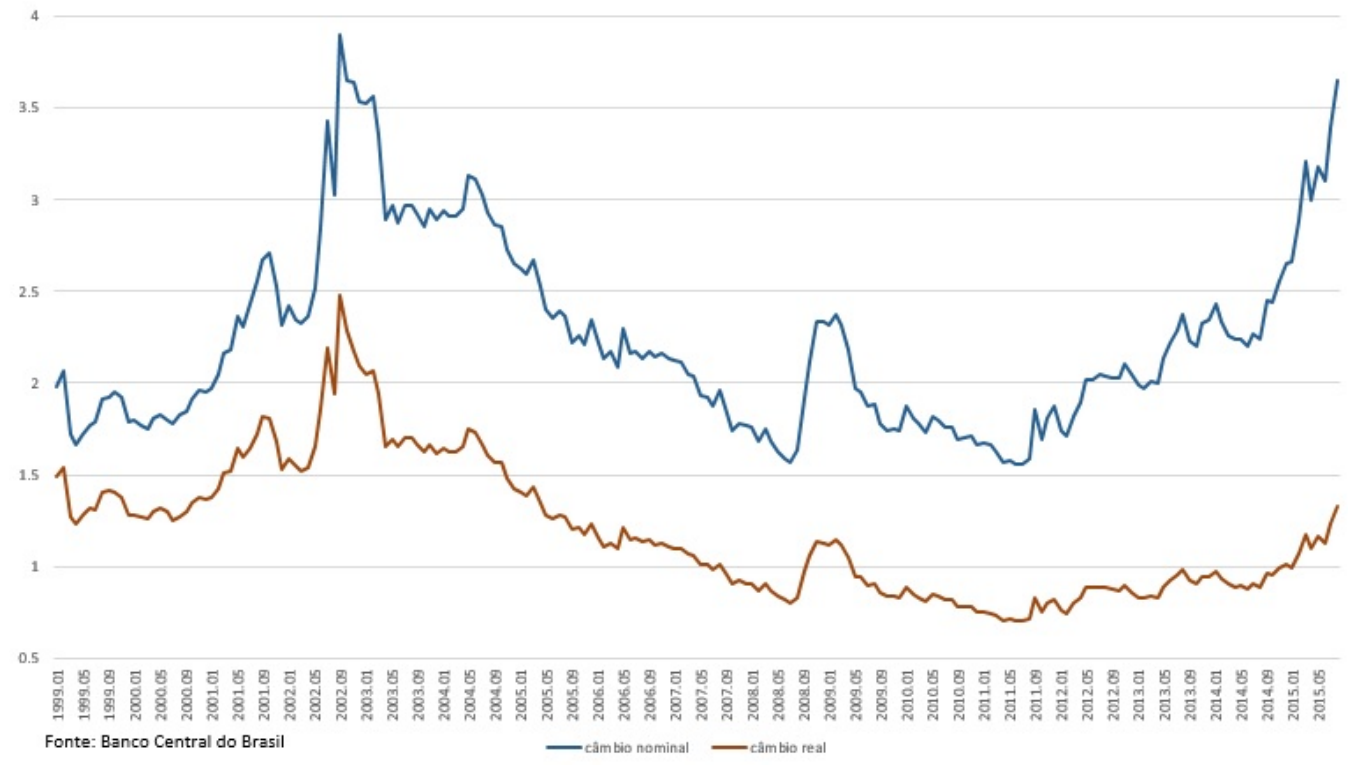


Figura 3: Participação do Crédito na Economia

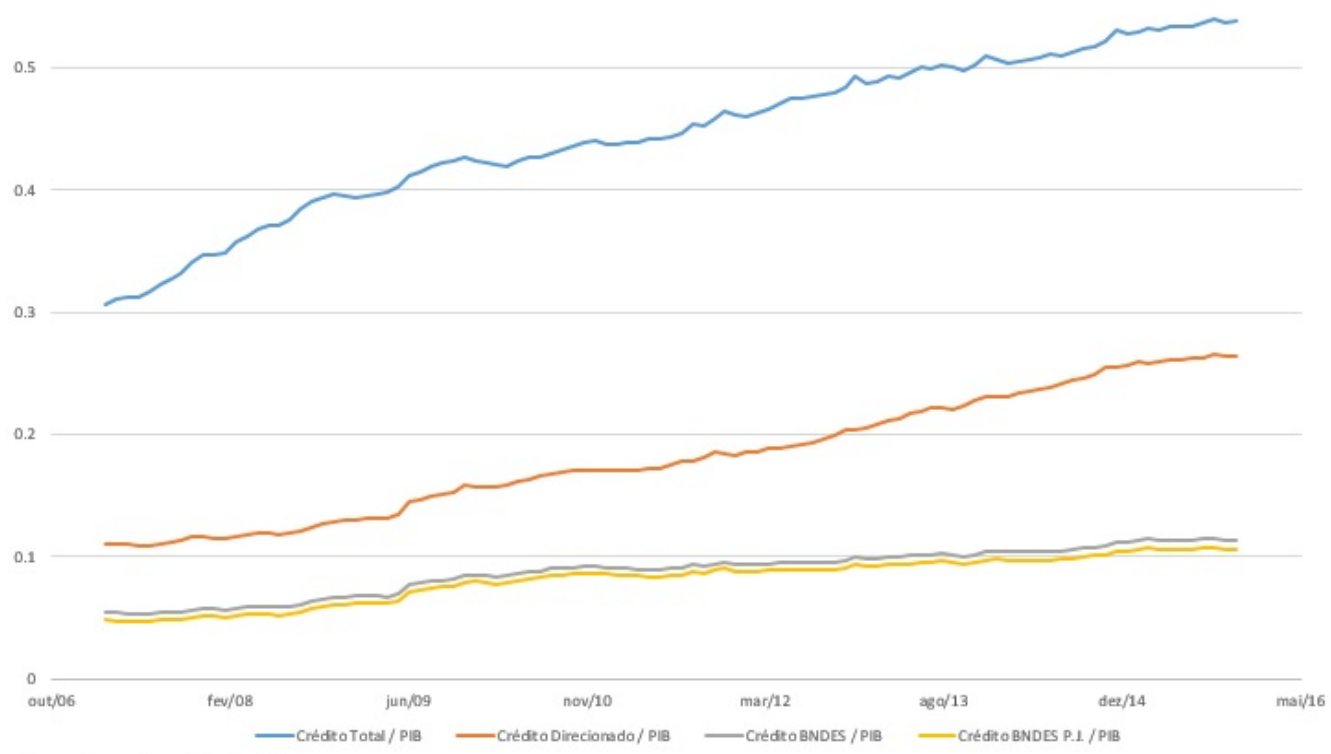

Fonte: Banco Central do Brasil

Figura 4: Participação do Crédito Direcionado no Mercado de Crédito

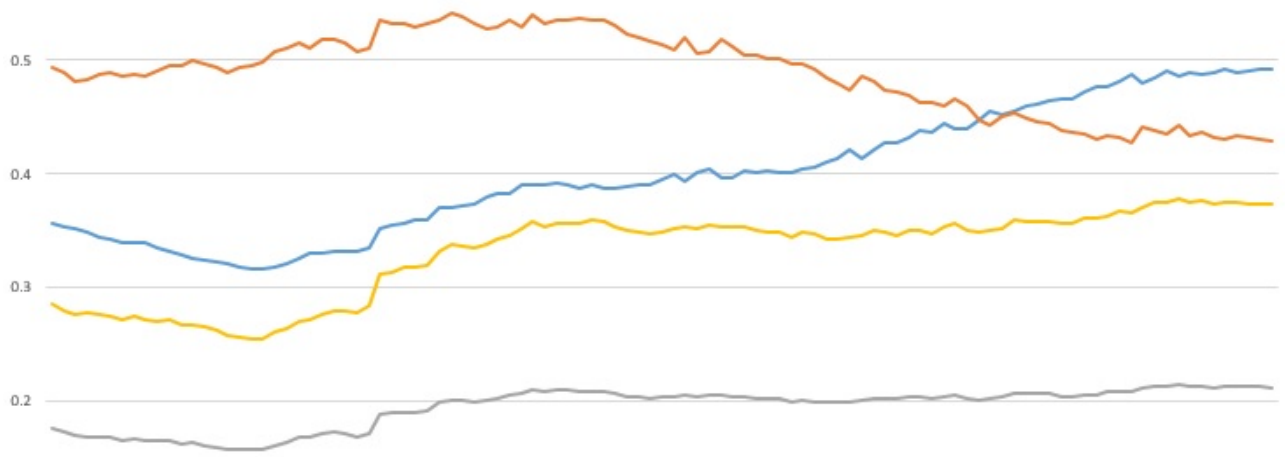

0.1

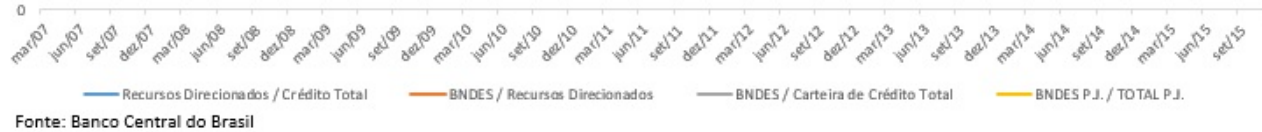
Fonte: Banco Central do Brasil 


\section{ANEXO B - Tabelas}

Tabela 1

Regressão Tobit para estimar a importância do tamanho da empresa, do impacto da volatilidade do câmbio e de outras caracteristicas individuais das empresas no uso de crédito em moeda estrangeira. Regressão estimada com base num painel montado com observações trimestrais das empresas brasileiras listadas na Bolsa
de Valores
de São
Paulo
entre
1999
2015

Variável Dependente: Dívida em Moeda Estrangeira / Dívida Total

\begin{tabular}{|c|c|c|c|c|}
\hline $\operatorname{Ln}(\mathrm{K})$ & $\begin{array}{l}0.0257^{* \cdots} \\
(5.51)\end{array}$ & $\begin{array}{l}0.0265^{* \cdots} \\
(5.31)\end{array}$ & $\begin{array}{l}0.0251^{* \cdots} \\
(5.06)\end{array}$ & $\begin{array}{l}0.0221 \cdots \\
(4.48)\end{array}$ \\
\hline $\operatorname{Ln}(\mathrm{K})^{*}$ vol_câmbio & $\begin{array}{l}-0.0128 \\
(-0.29)\end{array}$ & $\begin{array}{l}-0.0129 \\
(-0.29)\end{array}$ & $\begin{array}{l}-0.00910 \\
(-0.21)\end{array}$ & $\begin{array}{l}-0.0120 \\
(-0.27)\end{array}$ \\
\hline d_imob & & $\begin{array}{l}-0.00953 \\
(-0.46)\end{array}$ & $\begin{array}{l}-0.00151 \\
(-0.07)\end{array}$ & $\begin{array}{l}-0.0123 \\
(-0.60)\end{array}$ \\
\hline d_comer & & & $\begin{array}{l}0.175^{* \cdots} \\
(5.66)\end{array}$ & $\begin{array}{l}0.196 * \cdots \\
(6.35)\end{array}$ \\
\hline d_adr & & & & $\begin{array}{l}0.252^{\cdots} \cdots \\
(4.74)\end{array}$ \\
\hline _cons & $\begin{array}{l}-0.419 * \cdots \\
(-6.69)\end{array}$ & $\begin{array}{l}-0.428 \cdots \\
(-6.50)\end{array}$ & $\begin{array}{l}-0.502 \\
(-7.56)\end{array}$ & $\begin{array}{l}-0.495 * \cdots \\
(-7.56)\end{array}$ \\
\hline $\mathrm{N}$ & 5064 & 5064 & 5064 & 5064 \\
\hline $\begin{array}{l}\text { estatistica t entre pa } \\
{ }^{*} \mathrm{p}<0.05\end{array}$ & ${ }^{e s} \mathrm{p}<0.01$ & $* * * 0<0.00$ & & \\
\hline
\end{tabular}

Tabela 2

Regressão Tobit para estimar a importância do tamanho da empresa, do impacto da volatilidade da inflação e de outras caracteristicas individuais das empresas no acesso das mesmas a financiamentos de longo prazo. Regressão estimada com base num painel montado com observações trimestrais das empresas brasileiras listadas na Bolsa de Valores de São Paulo entre 1999 e 2015

Variável Dependente: Dívida de Longo Prazo / Dívida Total

\begin{tabular}{|c|c|c|c|c|}
\hline $\operatorname{Ln}(\mathrm{K})$ & $\begin{array}{l}0.0243^{* \cdots} \\
(8.23)\end{array}$ & $\begin{array}{l}0.0231^{\cdots *} \\
(7.37)\end{array}$ & $\begin{array}{l}0.0242^{* \bullet \bullet} \\
(7.69)\end{array}$ & $\begin{array}{l}0.0233^{\cdots \cdots} \\
(7.35)\end{array}$ \\
\hline $\operatorname{Ln}(\mathrm{K})^{*}$ vol_inflação & $\begin{array}{l}-0.209 \\
(-0.68)\end{array}$ & $\begin{array}{l}-0.207 \\
(-0.67)\end{array}$ & $\begin{array}{l}-0.206 \\
(-0.67)\end{array}$ & $\begin{array}{l}-0.214 \\
(-0.70)\end{array}$ \\
\hline d_imob & & $\begin{array}{l}0.0188 \\
(1.09)\end{array}$ & $\begin{array}{l}0.0150 \\
(0.87)\end{array}$ & $\begin{array}{l}0.00849 \\
(0.49)\end{array}$ \\
\hline d_comer & & & $\begin{array}{l}-0.0647^{* \bullet} \\
(-3.15)\end{array}$ & $\begin{array}{l}-0.0585^{*} \\
(-2.83)\end{array}$ \\
\hline d_adr & & & & $\begin{array}{l}0.0860^{*} \\
(2.30)\end{array}$ \\
\hline _cons & $\begin{array}{l}0.290 \cdots \\
(7.66)\end{array}$ & $\begin{array}{l}0.302 \cdots \\
(7.65)\end{array}$ & $\begin{array}{l}0.323^{\cdots \cdots} \\
(8.04)\end{array}$ & $\begin{array}{l}0.325 * \cdots \\
(8.12)\end{array}$ \\
\hline $\mathrm{N}$ & 5064 & 5064 & 5064 & 5064 \\
\hline $\begin{array}{l}\text { estatistica t entre } p \\
* \mathrm{p}<0.05\end{array}$ & ** $p<0.01$ & $* * * p<0.00$ & & \\
\hline
\end{tabular}


Tabela 3

Regressão para estimar os efeitos patrimoniais de flutuações cambiais que podem ser observadas no investimento das empresas. As primeiras 4 colunas não possuem a variável de investimento defasada. Regressão estimada com base num painel montado com observações trimestrais das empresas brasileiras listadas na Bolsa de Valores de São Paulo entre 1999 e 2015.

Variável Dependente: investimento

\begin{tabular}{|c|c|c|c|c|c|c|c|c|}
\hline & OLS & OLS-FE & GMM-dif & GMM-sys & OLS & OLS-FE & GMM-dif & GMM-sys \\
\hline lag_invest & & & & & $\begin{array}{l}0.00384^{\cdots \cdots} \\
(4.59)\end{array}$ & $\begin{array}{l}0.00363^{\cdots \cdots} \\
(5.75)\end{array}$ & $\begin{array}{l}0.0125 \cdots \cdots \\
(4.03)\end{array}$ & $\begin{array}{l}0.0156^{* \cdots} \\
(5.73)\end{array}$ \\
\hline (D* / lag_K)*var_câmbio & $\begin{array}{l}-0.000653^{\cdots *} \\
(-15.14)\end{array}$ & $\begin{array}{l}-0.000395 * \cdots \\
(-8.38)\end{array}$ & $\begin{array}{l}0.00224 \\
(0.31)\end{array}$ & $\begin{array}{l}-0.000991 \\
(-0.24)\end{array}$ & $\begin{array}{l}-0.000535 \cdots \\
(-11.80)\end{array}$ & $\begin{array}{l}-0.000255 \cdots \\
(-5.16)\end{array}$ & $\begin{array}{l}0.00142 \\
(0.37)\end{array}$ & $\begin{array}{l}-0.00102 \\
(-0.44)\end{array}$ \\
\hline $\operatorname{lag}\left(\mathrm{D}^{*} / \mathrm{K}\right)$ & $\begin{array}{l}-0.00000221 * \\
(-2.59)\end{array}$ & $\begin{array}{l}-0.00000207 \\
(-0.30)\end{array}$ & $\begin{array}{l}0.00000535 \\
(0.04)\end{array}$ & $\begin{array}{l}-0.00000697 \\
(-0.14)\end{array}$ & $\begin{array}{l}0.000000482 \\
(1.10)\end{array}$ & $\begin{array}{l}0.00000313 \\
(0.84)\end{array}$ & $\begin{array}{l}-0.0000113 \\
(-0.14)\end{array}$ & $\begin{array}{l}-0.00000839 \\
(-0.31)\end{array}$ \\
\hline $\operatorname{lag}\left(D_{-} t / K\right)$ & $\begin{array}{l}-0.00000184 \cdots \\
(-4.95)\end{array}$ & $\begin{array}{l}0.000000196 \\
(0.06)\end{array}$ & $\begin{array}{l}0.0000191 \\
(0.47)\end{array}$ & $\begin{array}{l}-0.00000347 \\
(-0.42)\end{array}$ & $\begin{array}{l}-0.00000207 * \cdots \\
(-15.26)\end{array}$ & $\begin{array}{l}-0.00000101 \\
(-0.58)\end{array}$ & $\begin{array}{l}0.0000197 \\
(0.88)\end{array}$ & $\begin{array}{l}-0.00000283 \\
(-0.62)\end{array}$ \\
\hline var_câmbio & $\begin{array}{l}-0.895 * \cdots \\
(-3.78)\end{array}$ & $\begin{array}{l}0 \\
\text { (.) }\end{array}$ & $\begin{array}{l}0 \\
\text { (.) }\end{array}$ & $\begin{array}{l}0 \\
\text { (.) }\end{array}$ & $\begin{array}{l}-0.927^{* \cdots} \\
(-3.79)\end{array}$ & $\begin{array}{l}0 \\
\text { (.) }\end{array}$ & $\begin{array}{l}0 \\
\text { (.) }\end{array}$ & $\begin{array}{l}0 \\
\text { (.) }\end{array}$ \\
\hline d_adr & $\begin{array}{l}-0.00899 \\
(-0.27)\end{array}$ & $\begin{array}{l}0 \\
(.)\end{array}$ & $\begin{array}{l}0 \\
(.)\end{array}$ & $\begin{array}{l}1.021 \\
(1.20)\end{array}$ & $\begin{array}{l}-0.0259 \\
(-0.72)\end{array}$ & $\begin{array}{l}0 \\
\text { (.) }\end{array}$ & $\begin{array}{l}0 \\
\text { (.) }\end{array}$ & $\begin{array}{l}-0.128 \\
(-0.32)\end{array}$ \\
\hline d_imob & $\begin{array}{l}0.0307 \\
(1.05)\end{array}$ & $\begin{array}{l}0.0762 \\
(1.61)\end{array}$ & $\begin{array}{l}-3.844 * \cdots \\
(-5.09)\end{array}$ & $\begin{array}{l}-1.241^{*} \\
(-2.20)\end{array}$ & $\begin{array}{l}0.0521 \\
(1.63)\end{array}$ & $\begin{array}{l}0.0975^{*} \\
(2.08)\end{array}$ & $\begin{array}{l}-1.661 * \cdots \\
(-4.06)\end{array}$ & $\begin{array}{l}-0.310 \\
(-1.06)\end{array}$ \\
\hline d_comer & $\begin{array}{l}-0.0905 * * \\
(-3.23)\end{array}$ & $\begin{array}{l}0 \\
\text { (.) }\end{array}$ & $\begin{array}{l}0 \\
\text { (.) }\end{array}$ & $\begin{array}{l}-0.198 \\
(-1.53)\end{array}$ & $\begin{array}{l}-0.0912 * \bullet \\
(-2.89)\end{array}$ & $\begin{array}{l}0 \\
\text { (.) }\end{array}$ & $\begin{array}{l}0 \\
\text { (.) }\end{array}$ & $\begin{array}{l}-0.170^{*} \\
(-2.38)\end{array}$ \\
\hline _cons & $\begin{array}{l}0.266^{\circ \cdots} \\
(7.30)\end{array}$ & $\begin{array}{l}-0.0613 \\
(-1.38)\end{array}$ & & $\begin{array}{l}0.324 \\
(0.89)\end{array}$ & $\begin{array}{l}0.263^{* \cdots} \\
(6.81)\end{array}$ & $\begin{array}{l}0.0954 \cdots \\
(3.86)\end{array}$ & & $\begin{array}{l}0.209 \\
(1.14)\end{array}$ \\
\hline $\mathrm{N}$ & 4216 & 4216 & 3931 & 4216 & 3931 & 3931 & 3639 & 3931 \\
\hline
\end{tabular}

Tabela 4

Regressão para estimar os efeitos patrimoniais de flutuações cambiais que podem ser observadas no investimento das empresas. As primeiras 4 colunas não possuem a variável de investimento defasada. Regressão estimada com base num painel montado com observações trimestrais das empresas brasileiras listadas na Bolsa de Valores de São Paulo entre $2010 \quad$ e 2015.

Variável Dependente: investimento

\begin{tabular}{|c|c|c|c|c|c|c|c|c|}
\hline & OLS & OLS-FE & GMM-dif & GMM-sys & OLS & OLS-FE & GMM-dif & GMM-sys \\
\hline lag_invest & & & & & $\begin{array}{l}0.000371 \\
(0.92)\end{array}$ & $\begin{array}{l}0.000206 \\
(0.78)\end{array}$ & $\begin{array}{l}-0.0191^{*} \\
(-2.19)\end{array}$ & $\begin{array}{l}0.0213^{* *} \\
(2.59)\end{array}$ \\
\hline$\left(D^{*} / \text { lag_K}\right)^{*}$ var_câmbio & $\begin{array}{l}-0.0103 \\
(-0.90)\end{array}$ & $\begin{array}{l}-0.00979 \\
(-0.86)\end{array}$ & $\begin{array}{l}-0.00979 \\
(-0.86)\end{array}$ & $\begin{array}{l}0.571^{* *} \\
(2.99)\end{array}$ & $\begin{array}{l}-0.0126 \\
(-1.12)\end{array}$ & $\begin{array}{l}-0.0125 \\
(-1.12)\end{array}$ & $\begin{array}{l}-0.0263 \\
(-0.43)\end{array}$ & $\begin{array}{l}1.203^{* * *} \\
(19.96)\end{array}$ \\
\hline $\operatorname{lag}\left(D^{*} / K\right)$ & $\begin{array}{l}0.00405 \\
(1.95)\end{array}$ & $\begin{array}{l}0.00407 \\
(1.70)\end{array}$ & $\begin{array}{l}0.00407 \\
(1.70)\end{array}$ & $\begin{array}{l}0.0640^{\cdots \cdots} \\
(5.70)\end{array}$ & $\begin{array}{l}0.00529^{*} \\
(2.48)\end{array}$ & $\begin{array}{l}0.00559^{*} \\
(2.41)\end{array}$ & $\begin{array}{l}0.136^{* \cdots} \\
(13.80)\end{array}$ & $\begin{array}{l}0.102 \cdots \\
(29.57)\end{array}$ \\
\hline $\operatorname{lag}\left(D_{-} t / K\right)$ & $\begin{array}{l}0.00000261 \\
(1.46)\end{array}$ & $\begin{array}{l}0.00000572 * \bullet \\
(3.03)\end{array}$ & $\begin{array}{l}0.00000572 * * \\
(3.03)\end{array}$ & $\begin{array}{l}0.0000219 \\
(0.63)\end{array}$ & $\begin{array}{l}0.00000370^{*} \\
(2.01)\end{array}$ & $\begin{array}{l}0.00000666^{* * *} \\
(3.44)\end{array}$ & $\begin{array}{l}0.000311 \cdots \\
(8.05)\end{array}$ & $\begin{array}{l}0.0000338 * * \\
(3.00)\end{array}$ \\
\hline var_câmbio & $\begin{array}{l}-1.689 * \cdots \\
(-5.90)\end{array}$ & $\begin{array}{l}0 \\
\text { (.) }\end{array}$ & $\begin{array}{l}0 \\
\text { (.) }\end{array}$ & $\begin{array}{l}0 \\
\text { (.) }\end{array}$ & $\begin{array}{l}-1.665^{* * 8} \\
(-5.81)\end{array}$ & $\begin{array}{l}0 \\
(.)\end{array}$ & $\begin{array}{l}0 \\
(.)\end{array}$ & $\begin{array}{l}0 \\
\text { (.) }\end{array}$ \\
\hline d_adr & $\begin{array}{l}0.00329 \\
(0.07)\end{array}$ & $\begin{array}{l}0 \\
\text { (.) }\end{array}$ & $\begin{array}{l}0 \\
\text { (.) }\end{array}$ & $\begin{array}{l}-1.829 \\
(-1.17)\end{array}$ & $\begin{array}{l}-0.00313 \\
(-0.07)\end{array}$ & $\begin{array}{l}0 \\
(.)\end{array}$ & $\begin{array}{l}0 \\
\text { (.) }\end{array}$ & $\begin{array}{l}-0.544 \\
(-1.20)\end{array}$ \\
\hline d_imob & $\begin{array}{l}-0.0599^{*} \\
(-2.10)\end{array}$ & $\begin{array}{l}-0.0182 \\
(-0.46)\end{array}$ & $\begin{array}{l}-0.0182 \\
(-0.46)\end{array}$ & $\begin{array}{l}0.682 \\
(0.79)\end{array}$ & $\begin{array}{l}-0.0583 \\
(-1.93)\end{array}$ & $\begin{array}{l}-0.0261 \\
(-0.65)\end{array}$ & $\begin{array}{l}-0.0548 \\
(-0.13)\end{array}$ & $\begin{array}{l}0.488 \\
(1.81)\end{array}$ \\
\hline d_comer & $\begin{array}{l}-0.127^{\cdots \cdots} \\
(-4.60)\end{array}$ & $\begin{array}{l}0 \\
\text { (.) }\end{array}$ & $\begin{array}{l}0 \\
\text { (.) }\end{array}$ & $\begin{array}{l}-0.123 \\
(-0.89)\end{array}$ & $\begin{array}{l}-0.131^{* * *} \\
(-4.55)\end{array}$ & $\begin{array}{l}0 \\
\text { (.) }\end{array}$ & $\begin{array}{l}0 \\
\text { (.) }\end{array}$ & $\begin{array}{l}-0.0327 \\
(-0.72)\end{array}$ \\
\hline _cons & $\begin{array}{l}0.274^{\cdots} \cdot \\
(7.65)\end{array}$ & $\begin{array}{l}0.230 \cdots \\
(10.48)\end{array}$ & $\begin{array}{l}0.230 \cdots \\
(10.48)\end{array}$ & $\begin{array}{l}0.0894 \\
(0.27)\end{array}$ & $\begin{array}{l}0.272 \cdots \\
(7.45)\end{array}$ & $\begin{array}{l}0.0813^{* \cdots} \\
(5.98)\end{array}$ & & $\begin{array}{l}-0.169 \\
(-1.62)\end{array}$ \\
\hline $\mathrm{N}$ & 5308 & 5308 & 5308 & 5308 & 4976 & 4976 & 4635 & 4976 \\
\hline $\begin{array}{l}\text { estatisticas t entre } \\
{ }^{*} \mathrm{p}<0.05\end{array}$ & & & & & $* * p<0.01$ & $* * * \mathrm{p}<0.001 "$ & & \\
\hline
\end{tabular}


Tabela 5

\begin{tabular}{|c|c|c|c|c|c|c|c|c|}
\hline & Empresas & $\begin{array}{c}\text { empresas } \\
\text { com D* }\end{array}$ & $\begin{array}{c}\text { empresas de } \\
\text { bens } \\
\text { comercializáveis } \\
\text { com } D^{*}\end{array}$ & $\mathrm{D} * / \mathrm{D}_{\mathrm{t}}$ & D lp/D t & $\begin{array}{l}\text { comer. com } \\
D^{*} / \text { total } D^{*}\end{array}$ & $\begin{array}{l}\text { empresas } \\
\text { com } D^{*} / \\
\text { total } \\
\text { empresas }\end{array}$ & $\begin{array}{c}\text { comer com } \\
\mathrm{D}^{*} / \text { total de } \\
\text { empresas }\end{array}$ \\
\hline 1995 & 94 & 4 & 3 & 0 & 0.38 & 0.750 & 0.043 & 0.032 \\
\hline 1996 & 146 & 8 & 7 & 0 & 0.41 & 0.875 & 0.055 & 0.048 \\
\hline 1997 & 160 & 8 & 6 & 0.01 & 0.48 & 0.750 & 0.050 & 0.038 \\
\hline 1998 & 229 & 123 & 89 & 0.19 & 0.57 & 0.724 & 0.537 & 0.389 \\
\hline 1999 & 244 & 148 & 99 & 0.21 & 0.59 & 0.669 & 0.607 & 0.406 \\
\hline 2000 & 245 & 152 & 106 & 0.22 & 0.6 & 0.697 & 0.620 & 0.433 \\
\hline 2001 & 259 & 163 & 114 & 0.22 & 0.61 & 0.699 & 0.629 & 0.440 \\
\hline 2002 & 252 & 164 & 112 & 0.24 & 0.6 & 0.683 & 0.651 & 0.444 \\
\hline 2003 & 249 & 165 & 110 & 0.23 & 0.6 & 0.667 & 0.663 & 0.442 \\
\hline 2004 & 250 & 163 & 105 & 0.22 & 0.6 & 0.644 & 0.652 & 0.420 \\
\hline 2005 & 254 & 148 & 97 & 0.18 & 0.6 & 0.655 & 0.583 & 0.382 \\
\hline 2006 & 281 & 144 & 93 & 0.15 & 0.61 & 0.646 & 0.512 & 0.331 \\
\hline 2007 & 305 & 163 & 105 & 0.15 & 0.64 & 0.644 & 0.534 & 0.344 \\
\hline 2008 & 300 & 165 & 104 & 0.14 & 0.63 & 0.630 & 0.550 & 0.347 \\
\hline 2009 & 302 & 147 & 94 & 0.1 & 0.62 & 0.639 & 0.487 & 0.311 \\
\hline 2010 & 301 & 100 & 57 & 0.09 & 0.62 & 0.570 & 0.332 & 0.189 \\
\hline 2011 & 302 & 106 & 63 & 0.12 & 0.61 & 0.594 & 0.351 & 0.209 \\
\hline 2012 & 300 & 107 & 63 & 0.13 & 0.62 & 0.589 & 0.357 & 0.210 \\
\hline 2013 & 304 & 101 & 61 & 0.12 & 0.63 & 0.604 & 0.332 & 0.201 \\
\hline 2014 & 301 & 102 & 61 & 0.11 & 0.63 & 0.598 & 0.339 & 0.203 \\
\hline 2015 & 296 & 98 & 59 & 0.13 & 0.61 & 0.602 & 0.331 & 0.199 \\
\hline
\end{tabular}

Tabela 6

Regressão para estimar os efeitos patrimoniais de flutuações cambiais que podem ser observadas no investimento das empresas. As primeiras 4 colunas não possuem a variável de investimento defasada. Regressão estimada com base num painel montado com observações anuais das empresas brasileiras listadas na Bolsa de Valores de São Paulo entre 1999 e 2015 controlando para exportações e importações a nivel de setor

Variável Dependente: investimento

\begin{tabular}{|c|c|c|}
\hline & GMM-dif & GMM-sys \\
\hline lag_invest & $\begin{array}{l}0.0751^{* * *} \\
(6.31)\end{array}$ & $\begin{array}{l}0.0725^{* * *} \\
(5.94)\end{array}$ \\
\hline (D* / lag_K)*var_câmbio & $\begin{array}{l}-3.840^{* * *} \\
(-19.71)\end{array}$ & $\begin{array}{l}-3.959 * * * \\
(-19.95)\end{array}$ \\
\hline $\operatorname{lag}\left(\mathrm{D}^{*} / \mathrm{K}\right)$ & $\begin{array}{l}0.668^{* * *} \\
(21.94)\end{array}$ & $\begin{array}{l}0.656^{* * *} \\
(21.25)\end{array}$ \\
\hline $\operatorname{lag}\left(D_{-} t / K\right)$ & $\begin{array}{l}-0.00514 \\
(-1.74)\end{array}$ & $\begin{array}{l}-0.00488 \\
(-1.62)\end{array}$ \\
\hline var_câmbio & $\begin{array}{l}0 \\
(.)\end{array}$ & $\begin{array}{l}0 \\
(.)\end{array}$ \\
\hline $\exp$ & $\begin{array}{l}0.0000159^{*} \\
(2.27)\end{array}$ & $\begin{array}{l}0.0000167^{*} \\
(2.33)\end{array}$ \\
\hline imp & $\begin{array}{l}-0.0000162 \\
(-1.68)\end{array}$ & $\begin{array}{l}-0.0000183 \\
(-1.85)\end{array}$ \\
\hline -cons & $\begin{array}{l}-0.0326 \\
(-0.42)\end{array}$ & $\begin{array}{l}-0.0392 \\
(-0.61)\end{array}$ \\
\hline $\mathrm{N}$ & 2222 & 2085 \\
\hline $\begin{array}{l}\text { estatisticas t entre parênteses } \\
{ }^{*} \mathrm{p}<0.05\end{array}$ & ${ }^{* *} \mathrm{p}<0.01$ & $* * * \mathrm{p}<0.001 "$ \\
\hline
\end{tabular}


Tabela 7

Regressão para estimar os efeitos patrimoniais de flutuações cambiais que podem ser observadas no investimento das empresas. As primeiras 4 colunas não possuem a variável de investimento defasada. Regressão estimada com base num painel montado com observações anuais das empresas brasileiras listadas na Bolsa de Valores de São Paulo entre 1999 e 2015 controlando para o Q de Tobin Variável Dependente: investimento

\begin{tabular}{|c|c|c|c|c|}
\hline & GMM - sys & GMM - sys & GMM - sys & GMM - sys \\
\hline lag_invest & $\begin{array}{l}0.0138^{* * *} \\
(5.11)\end{array}$ & $\begin{array}{l}0.0165^{* * 8} \\
(6.09)\end{array}$ & $\begin{array}{l}0.0157^{* * *} \\
(5.81)\end{array}$ & $\begin{array}{l}0.0132^{* * *} \\
(4.92)\end{array}$ \\
\hline q_tobin & $\begin{array}{l}0.00361 \\
(0.26)\end{array}$ & $\begin{array}{l}0.00455 \\
(0.33)\end{array}$ & $\begin{array}{l}-0.00274 \\
(-0.21)\end{array}$ & $\begin{array}{l}-0.00440 \\
(-0.33)\end{array}$ \\
\hline $\mathrm{FLX} \_\mathrm{CX} / \mathrm{K}$ & $\begin{array}{l}-0.000334 \\
(-0.39)\end{array}$ & & & $\begin{array}{l}-0.000504 \\
(-0.61)\end{array}$ \\
\hline$\left(D^{*} / \text { lag_K}\right)^{*}$ var_câmbio & & $\begin{array}{l}-0.000361 \\
(-0.18)\end{array}$ & $\begin{array}{l}-0.000834 \\
(-0.36)\end{array}$ & $\begin{array}{l}-0.000864 \\
(-0.38)\end{array}$ \\
\hline $\operatorname{lag}\left(D^{*} / \mathrm{K}\right)$ & & & $\begin{array}{l}-0.00000607 \\
(-0.22)\end{array}$ & $\begin{array}{l}-0.0000213 \\
(-0.78)\end{array}$ \\
\hline $\operatorname{lag}\left(D_{-} t / K\right)$ & & & $\begin{array}{l}-0.00000249 \\
(-0.55)\end{array}$ & $\begin{array}{l}0.00000451 \\
(1.00)\end{array}$ \\
\hline _cons & $\begin{array}{l}0.0691 \\
(0.38)\end{array}$ & $\begin{array}{l}0.0538 \\
(0.30)\end{array}$ & $\begin{array}{l}0.0185 \\
(0.11)\end{array}$ & $\begin{array}{l}0.0195 \\
(0.12)\end{array}$ \\
\hline $\mathrm{N}$ & 3926 & 3930 & 3930 & 3926 \\
\hline $\begin{array}{l}\text { estatisticas t entre parênte } \\
{ }^{*} \mathrm{p}<0.05\end{array}$ & $* * p<0.01$ & $* * * p<0.001$ & & \\
\hline
\end{tabular}

